\title{
Macrophage-Mediated Tissue Response Evoked By Subchronic Inhalation of Lead Oxide Nanoparticles Is Associated With The Alteration of Phospholipases C And Cholesterol Transporters
}

\section{Tereza Smutna}

Institute of Animal Physiology and Genetics Czech Academy of Sciences: Ustav zivocisne fyziologie a genetiky Akademie ved Ceske republiky

\section{Jana Dumkova}

Masaryk University Faculty of Medicine: Masarykova univerzita Lekarska fakulta

\section{Daniela Kristekova}

Masaryk University Faculty of Science: Masarykova univerzita Prirodovedecka Fakulta

\section{Lucie Vrlikova}

Institute of Animal Physiology and Genetics Czech Academy of Sciences: Ustav zivocisne fyziologie a genetiky Akademie ved Ceske republiky

\section{Bohumil Docekal}

Institute of Analytical Chemistry Czech Academy of Sciences: Ustav analyticke chemie Akademie Ved Ceske Republiky

\section{Pavel Mikuska}

Institute of Analytical Chemistry Czech Academy of Sciences: Ustav analyticke chemie Akademie Ved Ceske Republiky

\section{Lukáš Alexa}

Institute of Analytical Chemistry Czech Academy of Sciences: Ustav analyticke chemie Akademie Ved Ceske Republiky

\section{Adriena Jedlickova}

Institute of Animal Physiology and Genetics Czech Academy of Sciences: Ustav zivocisne fyziologie a genetiky Akademie ved Ceske republiky

\section{Zbynek Vecera}

Institute of Analytical Chemistry Czech Academy of Sciences: Ustav analyticke chemie Akademie Ved Ceske Republiky

\section{Kamil Krumal}

Institute of Analytical Chemistry Czech Academy of Sciences: Ustav analyticke chemie Akademie Ved Ceske Republiky

\section{Pavel Coufalik}


Institute of Analytical Chemistry Czech Academy of Sciences: Ustav analyticke chemie Akademie Ved Ceske Republiky

\section{Dalibor Vsiansky}

Masaryk University Faculty of Science: Masarykova univerzita Prirodovedecka Fakulta

\section{Samuel Zachej}

Tescan Orsay Holding as

\section{Marcela Buchtova ( $\sim$ buchtova@iach.cz)}

Institute of Animal Physiology and Genetics https://orcid.org/0000-0002-0262-6774

\section{Ales Hampl}

Masaryk University Faculty of Medicine: Masarykova univerzita Lekarska fakulta

\section{Research}

Keywords: lead oxide nanoparticles, inhalation, lung macrophages, liver macrophages, cholesterol metabolism

Posted Date: August 20th, 2021

DOl: https://doi.org/10.21203/rs.3.rs-800926/v1

License: (c) (1) This work is licensed under a Creative Commons Attribution 4.0 International License. Read Full License 


\section{Abstract}

\section{Background}

Inhalation of lead oxide nanoparticles (PbO NPs), which are emitted to the environment by hightemperature technological processes, heavily impairs target organs. These nanoparticles pass through the lung barrier and are distributed via the blood into secondary target organs, where they cause numerous pathological alterations. Here, we studied in detail, macrophages as specialized cells involved in the innate and adaptive immune response in selected target organs to unravel their potential involvement in reaction to subchronic PbO NP inhalation. In this context, we also tackled possible alterations in lipid uptake in the lungs and liver, which is usually associated with foamy macrophage formation.

\section{Methods}

Female mice CD-1 (ICR), as a model organism, were placed into whole-body inhalation chambers and continuously exposed to PbO NPs at a concentration of $0.956 \times 10^{6} \mathrm{NPs} / \mathrm{cm}^{3}$ for 11 weeks (24/7). At the end of the exposure period, target organs (lung, liver, kidney, and spleen) were collected for analyses.

\section{Results}

The histopathological analysis of PbO NP exposed lung revealed serious chronic inflammation of lung tissues. The number of foamy macrophages was significantly increased in lung, and they contained numerous cholesterol crystals. PbO NP inhalation induced changes in expression of phospholipases $\mathrm{C}$ (PLC) as enzymes linked to macrophage-mediated inflammation in lungs. In the liver, the subchronic inhalation of $\mathrm{PbO}$ NPs caused predominantly hyperemia, microsteatosis or remodeling of the liver parenchyma, and the number of liver macrophages was also significantly increased. The expression of a scavenger receptor CD36 and transporter ABCA1, which are associated with lipid metabolism, was significantly altered in the liver. No microscopic or serious functional kidney alterations were detected after subchronic PbO NP exposure and CD68 positive cells were present in the physiological mode in the interstitial tissues.

\section{Conclusion}

Our study determined the association of increased cholesterol and lipid storage in targeted tissues with the alteration of scavenger receptors and phospholipases $\mathrm{C}$ after subchronic inhalation of PbO NPs and uncovered processes, which contribute to steatosis in liver and foamy macrophages in lungs.

\section{Background}

Since the beginning of life, all living organisms are exposed to nanoparticles (NPs), objects which have at least one dimension ranging from $1 \mathrm{~nm}$ to $100 \mathrm{~nm}$, produced by a variety of combustion processes, such as forest fires or volcanic activity. However, at the beginning of the industrial revolution, the volumes of 
nanoparticles released to environment increased dramatically, and this is currently being further aggravated with the expansion of nanotechnologies [1]. Nanoparticles can thus be divided into nanoparticles that arise as unwanted products from industrial processes (such as combustion processes) and nanoparticles prepared for defined applications. Indeed, nanoparticles produced in large amounts as negative outcomes contribute significantly to environmental pollution [1].

Lead toxicity has been known for many years, but lead is still widely used, for example, in batteries, various alloys, or ammunition. Lead is also used as a construction material in the chemical industry, an additive in engine lubricating oils, or part of X-ray protective suits [2]. The main sources of lead in the air are combustion processes, transport and combustion of fossil fuels and waste. Lead is also part of cigarette smoke. In the workplace, people come into contact with lead at most when they are melting or recycling batteries. Additionally, lead nanoparticles (Pb NPs) and especially their oxides (PbO NPs) are used mainly in the electrochemical industry, for example, as semiconductors in LEDs, infrared detectors, and additives for lubricating oils $[3,4]$. In the air, the main sources of lead particles are automobiles and air transport, lead smelters, and the rapidly evolving electrical industry [1].

Previously, we focused on the effect of inhalation of PbO NPs as they can pose a serious threat to human health because of their size and specific characteristics $[3,5]$. The negative effect of subchronic PbO NP inhalation on animals was confirmed by morphological and functional changes predominantly in the lungs and liver $[5,6]$. As we observed an inflammatory response after subchronic $\mathrm{PbO} \mathrm{NP}$ inhalation in lung tissue in our previous studies [6,7], we wanted to further analyse the role of macrophages in this response. Macrophages are cells participating in all phases of the immune and inflammatory response, and they can be found in organs throughout the body. They represent specific immune cells responsible for identifying and removing foreign substances from the body and can be activated towards proinflammatory (M1) or anti-inflammatory (M2) phenotypes depending on the stimuli [8]. Members of phospholipases $C$ (PLC) are involved in intracellular and intercellular signalling to macrophage-mediated inflammation [9]. There is a total of six classes of PLC enzymes, with PLC $\beta, \delta$, and $\gamma$ being expressed in M1 and M2 macrophages. Individual types of macrophages then express a specific combinations of individual PLC. We have selected three isoforms of PLC: PLC 1 1, PLCY2, and PLC81 to study the effect of $\mathrm{PbO}$ NP inhalation on macrophage populations in the lung, liver, and kidney. PLC $\beta 1$ is expressed in both M1 and M2 macrophages similar to PLCY2, while PLC81 is expressed only in M1 macrophages [9].

Another noteworthy effect of subchronic PbO NP inhalation on animals observed in our previously published study [6] was the alteration in lipid metabolism. We detected steatosis in the liver and altered concentration of lipids in the blood (total cholesterol and triglycerides). Similarly, Alexiichuk and colleagues found decreased total lipid and cholesterol concentrations in the blood and also morphological changes in the liver upon 12-week subchronic exposure of rats to lead nanoparticles (10 $\mathrm{nm}$ and $30 \mathrm{~nm} \mathrm{PbS)} \mathrm{[10].} \mathrm{The} \mathrm{prolonged} \mathrm{abnormal} \mathrm{retention} \mathrm{of} \mathrm{lipids} \mathrm{in} \mathrm{the} \mathrm{liver} \mathrm{results} \mathrm{in} \mathrm{macrovesicular}$ or microvesicular steatosis and can lead to metabolic dysfunction, inflammation, and hepatic fibrosis [11]. In humans, exposure to other metals, such as cadmium, can cause modifications in lipid metabolism, including cholesterol; however, the underlying mechanisms are still not clear [12]. Therefore, 
in this study, we approach such previous findings further, with the aim to uncover the mechanisms of action of PbO NPs on cells, tissues, and organs that involve alterations in lipid metabolism.

\section{Results}

The main routes of NP entry into the body are inhalation, transdermal entry, and ingestion [13]. Absorption of NPs through the skin is rather minimal as skin represents an effective barrier compared to much more permeable gastrointestinal tract and lungs [14]. The lungs are the most effective primary gateway for NPs [15] therefore we used this pathway for NP exposure. The mice were placed in wholebody inhalation chambers where the concentration of NPs was $0.956 \times 10^{6} \mathrm{NPs} / \mathrm{cm}^{3}$. This unique system corresponds with real situations in how animals are exposed to NPs present in the air. Airborne NPs can come into contact with various parts of the body. Additionally, the animals take care of their fur so that oral exposure to inhaled NPs can be even higher than in humans. The estimated deposited dose over the 11 weeks inhalation period was $1.684 \mu \mathrm{g}$ of $\mathrm{PbO}$ per gram of mouse body weight (Table 1).

Table 1

Characterization of generated PbO NPs.

\begin{tabular}{|ll|}
\hline Characterization of PbO NPs & PbO \\
\hline Number concentration & $0.956 \times 10^{6} \mathrm{NPs} / \mathrm{cm}^{3}$ \\
\hline Surface area & $4.21 \times 10^{9} \mathrm{~nm}^{2} / \mathrm{cm}^{3}$ \\
\hline Mode & $34.6 \mathrm{~nm}$ \\
\hline Geometric mean diameter & $29.7 \mathrm{~nm}$ \\
\hline Geometric standard deviation & 1.69 \\
\hline Mass concentration & $149.3 \mu \mathrm{gbO} / \mathrm{m}^{3}$ \\
\hline Estimated deposited dose (after $11 \mathrm{w})$ & $1.684 \mu \mathrm{gbO} / \mathrm{g}$ \\
\hline
\end{tabular}

This value was calculated (Supplementary file 1) based on previously published methodology $[16,17,18]$. A surface area of the respiratory tract acquires increasing attention as an important parameter in assessing the toxicity of nanoparticles, and, recently, it has been presented as the most biologically relevant dose metric for NPs toxicity in the lung. Consequently, the deposition of NPs in the respiratory tract was studied to assess the toxicological impacts of NPs entering the lungs. The deposition of PbO NPs in the mouse respiratory tract was calculated using a multiple-path particle dosimetry (MPPD) model $[19,20]$ for monodisperse aerosol with a geometric mean diameter of $29.7 \mathrm{~nm}$ and mass concentration of $149.3 \mu \mathrm{g} / \mathrm{m}^{3}$ (Fig. 1, Table 1).

The surface area of PbO NPs deposited in the extrathoracic, tracheobronchial, and alveolar regions of the mouse respiratory tract is $20.4 \%, 9.76 \%$, and $23.2 \%$, respectively, in the lung. Further, the simulation of inhaled PbO NPs deposited in different parts of the human respiratory tract was performed (Fig. 1D). The 
deposition fractions were calculated by the International Commission on Radiological Protection (ICRP) deposition model for the extrathoracic, tracheobronchial, and alveolar region. The total surface area of generated $\mathrm{PbO}$ NPs (i.e., $4.21 \times 10^{9} \mathrm{~nm}^{2} / \mathrm{cm}^{3} ; \mathrm{S}_{\mathrm{T}}$ ) was calculated by scanning mobility particle sizer (SMPS) spectrometer software from a measured particle size distribution. The data show that the surface area of PbO NPs deposited in the lung alveolar region $\left(\mathrm{S}_{\mathrm{A}} ; 34.1 \%\right.$ of the total surface area of PbO NPs) is much higher than the surface area of NPs deposited in the extrathoracic $\left(\mathrm{S}_{\mathrm{ET}} ; 7.3 \%\right)$ and tracheobronchial $\left(\mathrm{S}_{\mathrm{TB}} ; 4.5 \%\right)$ regions. The sum of the surface area of the NPs deposited in the alveolar and tracheobronchial regions of the lungs results in the so-called lung-deposited surface area (LDSA). The LDSA $\left(\mathrm{S}_{\mathrm{TB}+\mathrm{A}}\right)$ corresponds to $38.5 \%$ of the total surface area of inhaled PbO NPs, while the sum of the surface area of the NPs deposited in the extrathoracic, tracheobronchial, and alveolar region forms $45.8 \%$ of the total surface area of inhaled PbO NPs.

The depositions calculated using the MPPD model for the extrathoracic, tracheobronchial, and alveolar regions of the mouse respiratory tract are different from those calculated with the ICRP model for the human respiratory tract, which is probably mainly due to different morphometry (i.e., mouse $\times$ human) and aerosol parameters (i.e., polydisperse aerosol in ICRP model $\times$ monodisperse aerosol in MPPD model) used in the given models.

The total bodyweight of mice was not changed after 11-week PbO NP inhalation; however, the lung weight coefficient significantly increased in PbO NP animals $(p<0.05$, Fig. 1). The weight coefficients of organs were expressed as wet weight of the organ $(\mathrm{g}) /$ dead body weight $(\mathrm{g}) \times 100$. The weight coefficient of kidney was also increased in PbO NP animals $(p<0.05$ in the case of right kidney, there was no significant difference for the left kidney). The other organ weight coefficients for liver and spleen were not significantly altered after PbO NP inhalation.

\section{The highest level of $\mathrm{Pb}$ after subchronic $\mathrm{PbO} \mathrm{NP}$ inhalation was found in the kidney and lung}

The content of $\mathrm{Pb}$ was significantly increased after 11 weeks of $\mathrm{PbO}$ NP inhalation compared to the controls (Table 2) in all target organs studied here. 
Table 2

Concentration of $\mathrm{Pb}$ in organs following 11 weeks of $\mathrm{PbO}$ NP inhalation.

\begin{tabular}{|llll|}
\hline & & ctr & PbO \\
\hline lung & range & $<$ LOD* & $2463-4432$ \\
& mean & & 3393 \\
& SD & & 733 \\
\hline liver & range & $<$ LOD* & $667-1281$ \\
& mean & & 937 \\
& SD & & 222 \\
\hline kidney & range & $<$ LOD* & $2679-4592$ \\
& mean & & 3502 \\
& SD & & 693 \\
spleen & range & $<$ LOD* & $512-1914$ \\
& mean & & 973 \\
& SD & & 551 \\
\hline
\end{tabular}

The highest concentration of $\mathrm{Pb}$ was found in the kidney; a comparable content of lead was detected in the lungs. The liver and spleen contained similar mean concentration of lead that was about 3.5-fold lower than the $\mathrm{Pb}$ level in the kidney and lungs. Remarkably, the spleen displayed the highest differences in the content of $\mathrm{Pb}$ among the individual animals. In the control animals, the levels of $\mathrm{Pb}$ were always below the limit of detection (LOD) in all organs.

\section{Inhalation of PbO NPs caused chronic inflammation in the lungs accompanied by massive cell infiltrates with abundant foamy macrophages}

After 11-week $\mathrm{PbO}$ NP inhalation, histopathological analysis of the lung revealed numerous changes indicating severe lung tissue damage (Fig. 2, Table S1), similar to that found after a 6-week PbO NP inhalation experiment in our previous study [21].

Here, we prolonged the exposure time to 11 weeks to particularly focus on more profound chronic inflammatory tissue reaction. As the result of 11-week exposure, the lungs exhibited remodeling of tissue, bronchiolitis and alveolitis, atelectasis, hyperemia and dilated blood vessels, alveolar emphysema, thickened septa, increased number of cells in the interstitium, and occasionally hemorrhage.

Siderophages were also found in lung tissue (Fig. 2). Moreover, inflammatory infiltrates were seen around bronchioles and blood vessels. As summarized in Table S1, the histopathological changes to lungs were all statistically significant $(p<0.001)$ when compared to air-inhaling controls. Severe morphological alterations of the lungs were also observed at ultrastructural level (Fig. 2). Necrotic bronchiolar cells, 
bronchioles with accumulated neutrophils and macrophages, alveoli with cellular debris and inflammatory cells, and damaged membranes of lung cells, completed the image of deviations in lung tissues.

Expectably, Green Trichrome staining confirmed collagen fibres only in the walls of the vessels and bronchioles in both control and PbO NP exposed animals. However, collagen fibres as well as other signs of fibrosis were absent in alveolar parenchyma after PbO NP exposure (Fig. 2).

As 11 days long inhalation have produced in lungs large inflammatory infiltrates with abundant macrophages (Table S2), we then focused on details of such inflammatory change. Neutrophilic granulocytes, macrophages, mast cells, and lymphocytes were the main groups of the immune cells found in PbO NP exposed animals. Lymphocytes were dominant cells present in lung infiltrates (Fig. 2). The number of neutrophils (visualized as MPO-positive cells) was increased in PbO NP exposed animals (Fig. $2 \mathrm{~J}-\mathrm{L}$ ), and similarly to lymphocytes, they accumulated predominantly in lung infiltrates. Additionally, neutrophils were observed in the bronchioles and within alveolar spaces after PbO NP inhalation. The number of mastocytes (as visualised by Toluidine Blue staining) was not significantly altered after 11-week PbO NP inhalation (Fig. 2M-0). Clusters of plasma cells (mature B-cells producing immunoglobulins) were found in vicinity of blood vessels and bronchioles (Fig. 2R). High amounts of alveolar surfactant revealed by transmission electron microscopy (TEM) further implies serious damage to lung function caused by 11-week exposure to PbO NPs.

Besides unraveling subcellular damage, TEM also confirmed the presence of metal NPs in the lungs after $\mathrm{PbO}$ NP inhalation, with lead nanoparticles accumulating predominantly in the endosomes of alveolar epithelial cells I (Fig. 2S-T).

\section{Increased numbers of foamy macrophages were associated with altered expression of phospholipase C genes}

Next, we focused on macrophages and their signalling since these cells are instrumental for all three phases of immune and inflammatory response: initiation, maintenance, and resolution [22]. In the animals exposed to PbO NP, enlarged macrophages were accumulated in the alveolar spaces, bronchioles, and interalveolar septa, with this accumulation being statistically significant $(p<0.05)$ as demonstrated by quantification of CD68 (marker of macrophages) cell positivity (Fig. 3A-C, Table S2).

A macrophage-mediated inflammatory response is regulated by phospholipase $C(P L C)$ signalling. Phospholipase $\mathrm{C}$ is a family of enzymes that hydrolyse phospholipids and are involved in intracellular and intercellular signal transduction. PLC $\beta$ signalling plays a role in the expression of pro-inflammatory chemokines. PLC 1 directly regulates the expression of monocyte chemoattractant protein-1 (MCP-1 or CCL2) [9]. Here, the expression of PLCB1 mRNA in the lungs after PbO NP inhalation was significantly downregulated $(p<0.05$, Fig. 3D). Phospholipases PLCY controls the maturation and function of $B$ and $T$ lymphocytes (PLCY1 for T-cells and PLCY2 for B-cells) [23]. Subchronic PbO NP inhalation induced a statistically significant upregulation of expression of PLCY2 mRNA $(p<0.05$, Fig. 3D). The effect of PLCy2 
upregulation on B-cells can explain the high accumulation of lymphocytes observed after $\mathrm{PbO} \mathrm{NP}$ inhalation in lungs (Fig. 2C, E). Clusters of plasma cells (activated B-cells) were found by the transmission electron microscopy in the alveolar septa in PbO NP exposed animals (Fig. 2R).

Phospholipase PLC81 has a different effect on macrophage function compared to the above mentioned PLC members, as it negatively regulates inflammatory response in macrophages [24]. In consonance with this fact, PLC $\delta 1$ mRNA was slightly (statistically non significantly) decreased in animals exposed to PbO NP (Fig. 3D).

A large number of macrophages exhibited the appearance of foamy cells with many cholesterol crystals and lipid droplets in their cytoplasm, as shown by TEM (Fig. 3). As lipid homeostasis plays a crucial role during the transformation of macrophages into foamy cells, we have further focused on possible changes in lipid metabolism. Macrophages have on their cytoplasmic membranes receptors that are responsible for cholesterol uptake represented by cluster of differentiation 36 (CD36) and scavenger receptor $A 1$ (SR-A1), and receptors that are responsible for cholesterol efflux represented by ATP-binding cassette (ABC) transporters ABCA1, ABCG1, and scavenger receptor B1 (SR-B1) [25]. The levels of mRNAs of these receptors remained mostly unaffected in animals exposed to PbO NP. The only exception was statistically nonsignificant increase in mRNA of $A b c g 1$. This suggests that other factors than receptor expression are responsible for cholesterol accumulation in lungs observed here, which will be necessary to follow in future.

\section{Microvesicular steatosis and increased cholesterol uptake develop in the liver upon PbO NP inhalation}

The liver represents the central organ of the main metabolic processes. Exposure to metal NPs can trigger toxic effects in the liver, as documented in our previous studies [26, 27]. Here, inhalation of PbO NP prolonged to 11 weeks caused major liver remodeling, focal dystrophy, hydropic degeneration, and vacuolization of hepatocytes (Fig. 4, Figure S1, Table S3).

Hepatocytes displayed pronounced anisocytosis and anisokaryosis. Hyperemia, sinusoid damage, and focal necrosis were also present. Animals exposed to PbO NPs contained in their liver parenchyma numerous macrophages, and necrotic foci with inflammatory leukocyte infiltrates, predominantly lymphocytes and neutrophils. Infiltration of immune cells was also observed in the portal areas. However, when histopathologically scored, the morphological alteration in liver parenchyma in animals exposed to $\mathrm{PbO}$ NP were not statistically significant in comparison to controls.

As visualized by Green Trichrome staining, the quantity of collagen fibers in the portal areas, walls of blood vessels, and bile ducts were about the same in the livers of control animals and animals exposed to PbO NP (Fig. 4D), documenting the absence of liver fibrosis.

Previously, we have observed liver steatosis in animals exposed to PbO NP for 6 weeks [7]. Here, subchronic 11-weeks long exposure to PbO NP also caused steatosis in their livers (Fig. 4G) with numerous lipid droplets scattered in cytosol of hepatocytes, as shown by TEM. Ito cells displayed large lipid vacuoles (Fig. 4H). 
Next, we analyzed receptors responsible for cholesterol uptake (CD36 and SR-A1) and cholesterol efflux ( $A B C A 1, A B C G 1$, and SR-B1) in the liver. In contrast to lungs, in the liver mRNA expression of scavenger receptor CD36 and transporter ABCA1 were significantly deregulated $(p<0.01$ and $p<0.05$, respectively, Fig. 4). The expression of other receptors remained unchanged.

Taken together, PbO NP inhalation caused both morphological and functional alterations to liver, including the imbalance of lipid metabolism.

\section{Inhalation of PbO NPs caused alterations in the number of liver macrophages}

Liver macrophages, called Kupffer cells, are resident cells localized along liver sinusoid endothelial cells. It was previously estimated that every 100 hepatocytes are accompanied by 20-40 macrophages [28]. Thus, Kupffer cells contribute to liver parenchyma as a major cellular component involved in the maintenance of hepatic and systemic homeostasis. We used immunohistochemical detection of CD68 to visualize Kupffer cells in the liver (Fig. 5A-E, Table S4).

The number of hepatic macrophages was significantly increased $(p<0.05)$ after 11 -week inhalation of PbO NPs (Fig. 5D).

We also measured expression of PLC genes in livers. Upon the exposure to PbO NPs, the levels of mRNAs for PLC $\beta 1$ and PLCY2 remained completely unchanged, while the level of PLC $\delta 1$ became modestly lowered (Fig. 5F).

\section{Energy dispersive X-ray (EDX) analysis differentiated lead particles from particles of iron in hepatocytes}

Hepatocytes are major liver cells that physiologically store iron, one of the biogenic metal elements. Ultrastructurally, the particles of iron can be seen in the hepatocyte cytoplasm in the form of individual local agglomerates of small primary particles [29]. As lead nanoparticles can also form agglomerates (size range approximately $40-50 \mathrm{~nm}$ ) of primary particles of $0.4-0.5 \mathrm{~nm}$ in diameter, we decided for EDX analysis to identify the chemical composition of particles observed by TEM.

Agglomerates of particles were randomly distributed in hepatocyte cytoplasm and mitochondria. Within one selected mitochondrion with agglomerates of particles, we analysed two different region of interest (ROI) windows (with and without agglomerates) by EDX. Spectra were compared with a reference sample and analyzed using Oxford AZtec. The presence of $\mathrm{Pb}$ was confirmed by comparing the reference Spectrum 31 (Fig. 5, without NPs) and non-reference Spectrum 30 (Fig. 5, with NPs) by increased signal at a spectral position of $\mathrm{Pb}$. Therefore, hepatocyte mitochondria contained agglomerates of lead nanoparticles (Fig. 5).

\section{Subchronic PbO NP exposure caused only minor changes to the kidney parenchyma, but blood vessels contained large lipid droplets}

Since $\mathrm{Pb}$ is mainly excreted by kidneys [30], the effects of inhalation of PbO NP to this organ was also studied. The concentration of $\mathrm{Pb}$ in the kidney was higher than in all organs studied here; however, only 
minor morphological changes were observed in the kidney after the 11-week PbO NP exposure (Fig. 6, Figure S2, Table S5), similar to the 6-week exposure [21].

In some animals exposed to PbO NP, the glomerular metaplasia (change of female-like flattened cells in glomerular parietal epithelium of Bowman's capsule to male-like cuboidal cells) was seen, dilatation of proximal tubules was observed in one animal, and mild inflammatory perivascular cell infiltrates were irregularly located in kidney cortex. The kidney medulla did not exhibit any pathological features. The amount of collagen fibers visualized by Green Trichrome in PbO NP inhaling animal was about the same as in the controls (Fig. 6).

At the ultrastructural level, the glomerular and tubular parts of nephrons were without alterations. The kidney filtration barrier exhibited a characteristic physiological appearance. Interestingly, large lipid vacuoles were present in some kidney blood vessels (Fig. 6). The renal tubules closely attached to such vessels were compressed and displayed damage to their epithelial lining. Accumulations of nanoparticles were seen in the epithelial cells of proximal tubules (Fig. 6).

Next, we analyzed the expression of receptors CD36, SR-A1, ABCA1, ABCG1, and SR-B1, similar to other target organs. In the kidney, only expression of ABCA1 mRNA was significantly lowered $(p<0.01$, Fig. 6$)$, the expression of other receptors remained at about the same level as in the controls. In both glomerular and tubular compartments of kidney the CD68-positive macrophages were scarce, with no difference between the control and PbO NP inhaling animals.

The expression of PLCB1, PLCY2, and PLC81 mRNAs in the kidney did not exhibit any significant changes upon the exposure of animals to PbO NPs.

\section{The exposure to PbO NP did not lead to alterations in spleen macrophage distribution and morphology}

After the 11-week $\mathrm{PbO}$ NP inhalation, the concentration of $\mathrm{Pb}$ in the spleen was at the same level as in the liver. However, histopathological analysis of the spleens of PbO NP inhaling animals did not unravel any significant changes (Fig. 7). The proportion of red and white pulp was about the same in both PbO NPexposed and control animals. CD68-positive cells were detected predominantly in the white pulp where macrophages typically reside. Collagen fibers were rare in splenic parenchyma in both PbO NP exposed and control animals. The only change observed in animals exposed to PbO NPs was increased number of megakaryoblasts and megakaryocytes in splenic parenchyma.

\section{Discussion}

Nanoparticles are now applied in practically all segments of human activity, including medicine, pharmaceutical production, food industry, cosmetics, building industry or electrical engineering, and their production is increasing. Nanoparticles are becoming a inseparable component of the environment [31] with also lead nanoparticles being widely used in the modern industry [32, 33, 34]. 
Metal nanoparticles exhibit the ability to easily cross cell membranes in exposed animals [26, 35, 36, 37]. From the lungs, nanoparticles are distributed by blood after a relatively short time to other tissues and organs $[21,38,39,40]$. Based on our data shown here, we may confirm that nanoparticles pass from the lungs to the blood and are distributed to target organs, where they induce further tissue alterations.

Most studies evaluating $\mathrm{Pb}$ distribution in body organs use administration of $\mathrm{Pb}$ in drinking water or food. Upon oral entry, $\mathrm{Pb}$ typically accumulates in three compartments: bone, blood, and soft organs. In soft organs, orally administered $\mathrm{Pb}$ distributes in the following order kidney $\rightarrow$ spleen $\rightarrow$ liver $[41,42]$. Deposition of $\mathrm{Pb}$ in skeletal elements upon oral as well as inhalation entry is well documented [2], so that here we focused our attention to soft organs.

Here, inhaled $\mathrm{Pb}$ nanoparticles were biodistributed and accumlated in soft organs in the same order as upon oral entry: kidney $\rightarrow$ spleen $\rightarrow$ liver. The concentration of $\mathrm{Pb}$ in the lung as the primary target organ was practically identical to the kidney. We have seen such similar accumulation of $\mathrm{Pb}$ in the lung and kidney also in our previous study at the end of 11 weeks of inhalation a higher concentration of PbO NPs [43]. In current study, the $\mathrm{Pb}$ concentration in the liver and also the spleen was about 3.5-fold lower compared to the lung and kidney. In our previous study [43], where only liver and not spleen was analyzed, such drop was about 4-fold.

The data produced here revealed the increased weight of the lungs and kidneys after subchronic PbO NP inhalation. The increased weight of the lung after PbO NP exposure was also documented by previous studies $[5,44]$. Although some small variation in kidney weight could also be due to organ dissection, we are confident that the increase observed here is caused by NP accumulation in the kidney and the highvolume blood supply of this organ [45]. It is of note that intraperitoneal application of $\mathrm{PbO} N P$ in rats also resulted in increased mass of their kidneys ( $\mathrm{g}$ kidney per $100 \mathrm{~g}$ body mass) [46].

When napoparticles are inhaled, the lung is indeed the organ that is exposed to their highest concentrations. The respiratory system has effective mechanims that respond to damaging agents present in the air. Both natural immune responses and antigen-specific reactions are components of animal immunity. Here, despite the activation of numerous mechanisms of protection, the inhalation of $\mathrm{PbO}$ NPs caused serious inflammatory changes in the lung tissue similarly to other metal nanoparticles that we have studies before, such as $\mathrm{CdO}$ or $\mathrm{TiO}_{2}[26,35,37,47]$. Profound changes to lungs including increased weight, inflammatory infiltrates, damage to pneumocytes, and accumulation of macrophages were previously observed in rats inhaling lead sulfide NPs [3]. Here, we also observed an increased numbers of macrophages and neutrophils in the lungs after PbO NPs but the numbers of mastocytes remained low as in the controls. In contrast, inhalation of soluble $\mathrm{Pb}$ nanoparticles represented by $\mathrm{Pb}\left(\mathrm{NO}_{3}\right)_{2}$ have lead to significant decrease in macrophage numbers [48]. From also other studies using other types of metal NPs ( $\mathrm{CeO}_{2} \mathrm{NPs}$, ZnONPs, NiONPs, and CuONPs) $[47,49]$ it is obvious that there is a major variablity in how lungs react to different NPs, so that their individual investigation is neccesary.

\section{Role of lung macrophages}


In alveoli, macrophages are primary cells that phagocytose pathogenic particles [50]. The number of macrophages after PbO NP inhalation increased similarly as was observed with intratracheal exposure to $\mathrm{TiO}_{2}$ or CdO nanoparticles $[35,51]$. The phagocytosis is dependent, among other things, on the absorbed particle size. Some studies found that phagocytosis by alveolar macrophages is less effective for small particles than larger ones [37]. Thus, although in our study, the amount of macrophages significantly increased after $\mathrm{PbO} N \mathrm{~N}$ inhalation, it may not truly represent an effective defence of the lungs against nanoparticles.

When nanoparticles are not phagocytosed, they are deposited into the lung cells. Following inhalation of $\mathrm{PbO}$ nanoparticles, we observed the largest amount of nanoparticles in type I pneumocytes, which is consonant with our previous findings on PbO NPs [43].

Alveolar macrophages, which become overloaded with lipids (predominantly cholesterol) are called lipidladen macrophages or foam cells. Foam macrophages typically form during pathological changes of vessels (atherosclerosis or arthritis) or after infections caused by pathogens, such as Mycobacterium tuberculosis, Toxoplasma, or Chlamydia [52]. The process of development of foam cells in arteries is partricularly well understood [53]. An accumulation of lipids from blood low-density lipoprotein particles (LDL) activates the endothelial cells, which attract monocytes to such affected areas. Monocytes invade into the intima, differentiate into macrophages while absorbing the altered lipids, and are finally modified into foam cells. Internalized lipids are cytotoxic to the macrophages so that they produce specific cytokines that ultimately trigger foam cell death. Dying foam cells atract another macrophages which further aggravate the disease.

With inflammatory disease, processes involved in the development of foam cells in the lung are not so well understood [52]. High-fat diet, lipid storage disease, and internalisation or degradation of surfactant lipids have all been suggested as potential sourcess of excessive accumulation of lipds [54]. Some studies have also demonstrated that microbiota, such as Mycobacterium, synthesise specific lipids called mycolic acids that induce foam cell formation [55]. Finding of Mycobacterium bacilli within lipid droplets in foam macrophages may support this machanims.

Here, the presence of foam macrophages in the lung after subchronic 11-week inhalation of PbO NP was not accompanied by changes to levels of mRNAs coding for molecules involved in cholesterol metabolism (CD36, SR-A1, SR-B1, Abca1, and Abcg1). With this, we may only speculate about the machanisms by the which foam cells develop in lungs exposed to PbO NPs.

Phospholipase $\mathrm{C}$ plays an important role in the regulation of both the adaptive and innate immune response of organisms. PLC $\beta 1$ is expressed in several different organs including lungs, and regulates the expression of monocyte chemoattractant protein (MCP-1) [9]. Here, increased number of macrophages in the lungs after 11-week inhalation was paralleled by decreased level of PLC $\beta 1$ mRNA, which may reflect reaching sufficient numbers of macrophages in lungs to maintain homeostasis. 
While PLCY1 is widely expressed in several tissues, PLCY2 expression is restricted to cells of the hemopoietic system [23]. Members of PLCY activate both lymphocytes of adaptive immunity and all cell types of innate immunity (macrophages, natural killer cells, mast cells, and neutrophils) [56]. The role of PLCY2 in macrophages is not clear; however, activation of PLCY2 in mast cells mediates degranulation and cytokine secretion, and in neutrophils, induces adhesion and cell spreading [56]. Here, we have seen statistically significant increase in expression of PLCY2 in animals exposed to PbO NPs, which may mediate activation of specific immunity through lymphocytes and also activation of more cell types involved in innate immunity. PLCס1 is expressed in M1 pro-inflammatory macrophages and not in M2 [9]. The studies suggest that PLC 1 negatively regulates the toll-like receptor (TLR) mediated inflammatory response in macrophages. Here, PLCס1 mRNA was lowered in animals exposed to PbO NPs so that may contribute to increased activity of M1 macrophages in their lungs.

$A B C$ transporters $A B C A 1$ and $A B C G 1$ play a major role in active free cholesterol efflux from cells, including macrophages [53]. In our study, the levels of mRNAs of both these ABC transporters in lungs were unchanged upon exposure to PbO NPs. We hypothesize that this may simply be caused by the long 11-week exposure leading to exhaustion of these cellular responses.

\section{Role of liver macrophages}

The liver is an organ involved in many important detoxification and metabolic processes. In our experiment, inhalation of PbO NPs caused dystrophy of hepatocytes, focal necrosis, immune cell infiltration, accumulation of megakaryocytes, hyperemia, and hepatocyte remodeling. Similar changes, including focal necrosis with immune cell infiltration and/or dystrophy of hepatocytes, were observed after exposure to metal nanoparticles, such as $\mathrm{CdO}$ NPs [26] and $\mathrm{CeO}_{2} \mathrm{NPs}$ [57]. Similar defects in the liver were also observed after chronic exposure to lead acetate trihydrate in rats [58]. Extramedullary hematopoiesis observed after inhalation of PbO NPs is atypical for healthy adult mice; however, it is often associated with toxic exposure and depletion $[59,60]$.

Membrane-bound scavenger receptors (SR) bind many ligands, including lipoproteins [61]. They have been classified into several classes according to their sequences (classes $A-J)$. Scavenger receptor family class A encompasses more members, including SR-A1. Besides their role in the internalization of lipoproteins and the formation of foam cells, they are also involved in phagocytosis and macrophage apoptosis [61]. SR-B1 is a multiligand membrane protein receptor. Some authors declare that the receptor SR-B1 is predominantly responsible for cholesterol efflux (transfer of cholesterol from cells to HDL) [25], and other researchers describe SR-B1 as a receptor mediating both efflux and influx of cholesterol from and into cells $[61,62]$.

SR-B2 (CD36) is a macrophage glycoprotein receptor for oxidized LDL (oxLDL) [63]. CD36 and SR-A are the main contributors to cholesterol uptake of oxidized and acetylated LDL in macrophages [64]. CD36 has many functions, including not only macrophage uptake of oxLDL but also platelet activation and aggregation, apoptosis, and inflammation as this receptor binds oxLDL, apoptotic cells and bacterial and fungal pathogens [61]. Further, CD36 cooperates with coreceptors, including the TLRs involved in 
recognising pathogen-associated molecular patterns derived from microbes and plays an important part in innate immunity $[61,65]$. Thus, scavenger receptor CD36 functions as a multiligand receptor present in many tissue types and is implicated in multiple biological processes [66]. In our study, CD36 became significantly increased in the liver of animals exposed to PbO NPs, similarly as was previously shown by in vitro experiments monocytes and macrophages treated by zinc oxide NPs. [67]. Unfortunately, we may only speculate about the impact of such increase of $\operatorname{CD} 36$, since this receptor combines multiple functions in lipid metabolism and innate immunity.

SR-D1 (CD68) is a glycosylated transmembrane protein receptor expressed in late endosomes and lysosomes in macrophages. It has also been identified as an oxLDL binding protein [65]. Although CD68 is commonly used as a marker of macrophages; its role in oxLDL processing is poorly understood. Here, we have observed higher numbers of CD68-positive cells in the liver of animals exposed to PbO NPs, with these cells harboring cholesterol crystals in their cytoplasm (as seen by TEM). The liver is also the centrum of lipid metabolism; thus, the disorder of lipid storage or metabolism is often considered a significant sign of hepatotoxicity [68]. Recent in vitro studies revealed altered cholesterol metabolism in macrophages upon their exposure to metal nanoparticles $[67,69]$. Exposure to zinc oxide NPs (ZnONPs) resulted in intracellular accumulation of lipids combined with increased levels of the receptors SR-A and CD36 (both mRNAs and proteins), which are both involved in the uptake of modified LDL, while no such changes were seen in macrophages exposed to titanium oxide $\left(\mathrm{TiO}_{2} \mathrm{NPs}\right)$ [67]. Curiously, silver NPs (AgNPs) reduced uptake of cholesterol by macrophages and decreased expression of mRNA for the receptor SR-B1 [69]. Obviously, chemistry, and possibly also other characteristics, of nanoparticles decide about their impact on cholesterol metabolism in macrophages.

It is clear from our previous studies that the effect of PbO NPs on lipid metabolism is uneasy to predict [6, 21]. Histology and ultrastructure of the liver as well as biochemical parameters of blood were surprisingly independent of the $\mathrm{Pb}$ dose and the length of exposure, which was similar to other studies displaying irregular lipid accumulation in the liver and an uneven pattern of lipid metabolism genes after $\mathrm{Pb}$ exposure [70]. Thus, the insight into the effect of $\mathrm{Pb}$ exposure on lipid metabolism requires additional research to elucidate the mechanisms in cellular lipid retention.

The expression of $A B C$ transporter $A B C A 1$ is regulated by liver $X$ receptor $\alpha$ and $\beta$ ( $L X R a$ and LXRB) [25]. Chronic exposure to $\mathrm{Pb}$ induced changes to mRNAs coding for lipid metabolism regulators and also LXRs in the liver [70]. In our study, the levels of LXR mRNAs in the liver were significantly decreased upon the exposure to PbO NPs. Correspondingly, under these conditions we have also observed a decrease in the expression of ABCA1 mRNA in the liver as well as in the kidney. Since ABCA1 mediates the transfer of cholesterol across the plasma membrane out of cell, the decrease in ABCA1 after the exposure to PbO NPs can lead to a higher accumulation of cholesterol in these organs.

\section{Kidney and macrophages}

The kidney is mainly responsible for filtering blood in order to remove waste substances from the body in the form of urine. Lead poisoning causes damage to the kidneys, which is often irreversible and may 
have fatal effects on the body. Lead toxicity initiates numerous functional changes in the kidney, such as dysfunction of the proximal tubules, and numerous morphological changes to renal tissue, such as development of interstitial fibrosis $[2,71]$. However, the effect of $\mathrm{Pb}$ in nanoparticle form at a cellular level has not been fully clarified. In our study, we observed only minor changes in renal tissue after PbO NP inhalation, which is rather unexpected, knowing the highest concentration of $\mathrm{Pb}$ found in the kidney (kidney $>$ lung $>$ liver $>$ spleen). Correspondingly to this finding, previously, we have not seen any microscopic changes to the kidneys of mice exposed for six weeks to CdO NPs [26]. Moreover, it should be noted that using TEM we saw only sporadic $\mathrm{PbO}$ nanoparticles in the kidney tissues. Thus, since the high concentration of $\mathrm{Pb}$ as measured by chemical analysis did not coincide with the non-frequent occurrence of $\mathrm{PbO}$ nanoparticles, we assume that most of the $\mathrm{Pb}$ in the kidney is converted to yet unidentified non-particulate form. It is of note that our previous study performed using laser ablation inductively coupled plasma mass spectrometry (LA-ICP-MS) revealed high amounts of $\mathrm{Pb}$ both in nanoparticle and ionic form in kidneys of animals exposed to PbO NPs [6].

Under high-glucose conditions (diabetes), metabolic diseases, and hemodynamic alterations, podocytes, mesangial cells as well as tubular epithelia produce chemokines, growth factors, and cytokines, including MCP-1 [72]. These factors promote the recruitment of monocytes from the circulation followed by infiltration of these cells into the kidney. PLC 1 directly regulates the expression of MCP-1 [9]. Typically, human chronic kidney diseases, such as lupus nephritis, is accompanied by increased number of CD $68^{+}$ cells in the interstitial tissues, and by increased expression of MCP-1 in the tubular [73] and the glomerular areas $[74,75]$. Patients suffering from diabetic nephropathy accumulate M1 macrophages in the interstitium and the glomerular areas, while M2 macrophages accumulate just in the interstitium [76]. The kidneys of animals exposed here to PbO NPs had slightly decreased expression of MCP-1 (not significantly) and unchanged numbers of $\mathrm{CD} 8^{+}$cells, which was the same effect as that seen here also for the lungs. The absence of any significant change in expression in the kidneys of animals exposed here to PbO NPs was also found for scavenger receptors (SR-A1 and SR-B1) and CD36, and also the kidneys were void of any obvious inflammatory alterations. Taken these findings together, we may conclude that although toxicity of $\mathrm{Pb}$ in kidneys is maximal compared to other soft organs, inhaled $\mathrm{PbO}$ in nanoparticulate form does not trigger tangible inflammatory responses in this organ.

\section{Conclusion}

The most dramatic effect of prolonged subchronic inhalation of $\mathrm{PbO}$ nanoparticles was profound alteration in lipid exchange and enhanced cholesterol storage seen in all studied organs. In the lungs, the typical sign was the occurrence of large foamy macrophages in the alveolar area and interstitial tissue. Since these changes are accompanied by a modified expression of scavenger receptors, it is likely that they are due to the disruption of lipid transport across the cell membrane. Disrupted efflux of lipids from the cells and their accumulation in the tissue macrophages was also seen in the liver, where it was paralleled by an abnormal expression of cholesterol transporters and phospholipases $\mathrm{C}$. 
Expectably, the inhaled nanoparticles were heavily accumulated in the lungs. Still, the nanoparticles were unevenly (selectively) accumulated in only type I pneumocytes, and not in macrophages and type II pneumocytes. This may be due to the morphology of type I pneumocytes adapted for gas exchange, also facilitating entry of nanoparticles in large quantities. Type II pneumocytes, although not harboring nanoparticles, were also affected as evidenced by overproduction of surfactant. Lung macrophages seemed to be somewhat suppressed as indicated by altered expression of several members of PLC family members, which typically regulate inflammatory response of this cell type. It may be concluded that lungs exhibit multifaceted difficulty preventing their effective response to the overload of alveoli with heavy metal nanoparticles.

In summary, this study provides a complex insight into the structural and regulatory elements underlying an inability of the immune system to properly react to nanoparticle exposure by their removal.

\section{Material And Methods}

\section{Animals}

Adult female mice (CD-1(ICR) BR strain) with an average weight of approximately $24 \mathrm{~g}$ (about 6-8 weeks old) at the beginning of the inhalation experiment were obtained from the Animal Facility of the Masaryk University (Brno, Czech Republic). Mice were allowed to acclimatise to laboratory conditions one week before the experiment. Commercial feed and drinking water were provided ad libitum. The experiment was approved by the Ethical Board of the Institute of Analytical Chemistry, v.v.i., Czech Academy of Sciences, Brno (Approval No. 64/2016, 15 August 2016).

\section{Preparation of PbO NPs}

$\mathrm{PbO}$ NPs were prepared in the same way as in our previous studies $[5,77]$. PbO NPs were generated continuously in situ in a hot-wall tube flow reactor using an evaporation-oxidation-condensation technique in which a ceramic crucible containing a small amount of lead wire was placed inside the ceramic work tube of a vertically oriented furnace (Carbolite TZF 15/50/610). The molten lead was evaporated at the centre of the furnace at a temperature of $830^{\circ} \mathrm{C}$. The resulting metal vapour condensed to form Pb NPs that were carried out of the furnace by an inert nitrogen gas stream and diluted with a stream of air, during which the lead was oxidised to lead oxide. Both flow rates were set at $3 \mathrm{~L} / \mathrm{min}$ using mass flow controllers. The resulting PbO NPs were diluted in the second step by a stream of air (20 $\mathrm{L} / \mathrm{min}$ ) and used for whole-body inhalation experiments.

\section{Exposure to PbO NPs}

Inhalation chambers have been described in previous studies $[5,77]$. Ten experimental adult female mice were continuously exposed to PbO NPs at a concentration of $0.956 \times 10^{6} \mathrm{NPs} / \mathrm{cm}^{3}$ for 11 weeks (24 $\mathrm{h} /$ day, seven days/week). Ten control animals were exposed to the same air as treated animals but without the addition of $\mathrm{PbO}$ nanoparticles. The food for animals was sealed in special boxes protected from the deposition of nanoparticles from the air. 
At the end of inhalation periods, mice were sacrificed, and the lungs, livers, kidneys, and spleens were weighed and collected for chemical, histopathological, histochemical, ultramicroscopic, immunohistochemical analyses and to study the gene expression of selected markers.

\section{Characterisation of generated PbO NPs}

The main characterisation of generated PbO NPs is presented in Table 1 and Fig. 1. The distribution of NPs concerning particle number concentration was continuously measured directly inside the exposure cages using a scanning mobility particle sizer (SMPS; model 3936L72, TSI Inc., Shoreview, MN, USA). The long-term stability of PbO NPs generation was high. The mass concentration of PbO NPs was $149.3 \mu \mathrm{g}$ $\mathrm{PbO} / \mathrm{m}^{3}$ during the inhalation experiment. The mass concentration of generated $\mathrm{PbO}$ NPs was calculated by dividing the mass of PbO NPs collected on the filter by the volume of the air sample that passed through the filter.

Generated PbO NPs were sampled on nitrocellulose filters (pore size $0.45 \mu \mathrm{m}$, diameter $25 \mathrm{~mm}$, Millipore, Bedford, MA, USA). Filters were dissolved in $\mathrm{HNO}_{3}$ using a UniClever microwave mineraliser (Plazmatronika, Wroclaw, Poland), and the $\mathrm{Pb}$ content in the sample was determined using an atomic absorption spectrometry (AAS; AAnalyst 600, Perkin Elmer Inc., Shelton, CT, USA).

The size and shape of PbO NPs were characterised by electron microscopy (EM). Immediately after generation at the furnace output, PbO NPs were collected by electrostatic precipitation using a Nanometer aerosol sampler (model 3089, TSI) on EM grids (copper S160-4, 3 mm in diameter, 400 mesh grids, Agar Scientific, Electron Technology, Stansted, Essex, UK). The samples were analysed using a Magellan $400 \mathrm{~L}$ XHR microscope (FEl Company, Hillsboro, OR, USA), operating in the scanning transmission electron microscope (STEM) mode. The STEM results show that the PbO NPs observed in the gas phase by an SMPS were formed from agglomerates (size range approximately $40-50 \mathrm{~nm}$ ) of primary particles of $0.4-$ $0.5 \mathrm{~nm}$ in diameter (Fig. 1).

\section{Histological analysis}

Samples of target organs (lung, liver, kidney, and spleen) were fixed overnight in $10 \%$ buffered neutral formaldehyde in a fridge. After that, samples were dehydrated using a series of increasing concentrations of ethanol, then immersed in xylene, and embedded in paraffin wax. Serial histological sections of $5 \mu \mathrm{m}$ thickness were prepared and stained using standard Hematoxylin-Eosin staining. Selected sections were stained by Masson Green Trichrome (lungs and liver) for collagen fibres analysis and/or by Toluidine Blue staining for mastocytes demonstration (lungs). The sections were examined by light microscopy in a blinded fashion by two histologists. We evaluated at least 8-10 slides per organ in five animals from the control group and five animals from the PbO NP treated group and assessed alterations in histopathological changes in whole sections of the lungs, liver, and kidney (Table S1, Table S3, Table S5).

Photos of the samples were taken using a light microscope (Leica DM5000 B, Leica Microsystem GmbH, Vienna, Austria) with a digital colour camera (Leica DFC480, Leica Microsystem GmbH, Vienna, Austria). 


\section{Immunohistochemistry}

After deparaffinisation and rehydration of the sections in xylene and decreasing concentrations of ethanol, citrate buffer $(\mathrm{pH}=6)$ was used as a pre-treatment in a $97^{\circ} \mathrm{C}$ water bath. After that, sections were incubated with a blocking serum (VECTASTAIN ABC Kit, Rabbit IgG, PK-4001, Vector Laboratories, Burlingame, CA, USA; VECTASTAIN ABC Kit, Mouse IgG, PK-4002, Vector Laboratories, Burlingame, CA, USA) for $20 \mathrm{~min}$ at room temperature (RT), and then incubated with the primary antibody (MPO, CD68; detailed information Table S6).

After incubation of biotinylated secondary antibody (VECTASTAIN ABC Kit, Rabbit IgG, PK-4001, Vector Laboratories, Burlingame, CA, USA; VECTASTAIN ABC Kit, Mouse IgG, PK-4002, Vector Laboratories, Burlingame, CA, USA) for 30 min at RT, the peroxidase-conjugated avidin-biotin complex (VECTASTAIN ABC Kit, Rabbit IgG, PK-4001, Vector Laboratories, Burlingame, CA, USA; VECTASTAIN ABC Kit, Mouse IgG, PK-4002, Vector Laboratories, Burlingame, CA, USA) was applied for 30 min at RT. For visualisation of positive cells, chromogen substrate diaminobenzidine (Liquid DAB + Substrate Chromogen System, K3468, DAKO, Carpinteria, CA, USA) was used. Then, we counterstained samples with hematoxylin.

Photos of samples were taken using a light microscope (Leica DM5000 B, Leica Microsystem GmbH, Vienna, Austria) with a digital colour camera (Leica DFC480, Leica Microsystem GmbH, Vienna, Austria). The number of macrophages in the lungs and liver is presented as the mean \pm SD. Analyses were performed on four mice per control group and PbO NP group (Table S2, Table S4). The values of CD68+ macrophages were counted per square millimetre. The number of CD68 + macrophages was evaluated from four slides (10 images/slide) in each animal. The total area of analysed lungs and livers was 3.346 $\mathrm{mm}^{2}$ per animal.

\section{qRT-PCR analysis}

For RNA extraction, the RNeasy Plus Mini Kit (Cat. No. 74136, Qiagen, Germantown, MD, USA) was used. Complementary DNA was prepared according to the manufacturer's instructions using a gb Elite Reverse Transcription Kit (cat. No. 3012, Generi Biotech, CR). qRT-PCR was performed with a LightCycler® 480 (Roche). The number of analysed cDNA samples was 4-5 for the control or PbO NP group.

Gene expression values were expressed in terms of the threshold cycle normalised to beta-actin (Actb; ID Mm00607939_s1) expression. TaqMan® Gene Expression Assays (cat. No. 4351372, Applied Biosystems, USA) for CD-36 (ID: Mm01135202_g1), SR-A1 (ID: Mm00491755_m1), Abca1 (ID: Mm00442646_m1), Abcg1 (ID: Mm00437390_m1), SR-B1 (ID: Mm00450234_m1), PLCB1 (ID: Mm01329380_m1), PLCS1 (ID: Mm01342462_g1), PLCY2 (ID: Mm01242530_m1) were used, and gene expression was analysed with the following program: initial activation step at $95^{\circ} \mathrm{C}$ for $10 \mathrm{~min}$, followed by 45 cycles at $95^{\circ} \mathrm{C}$ for $15 \mathrm{~s}$, and annealing temperature at $60^{\circ} \mathrm{C}$ for $60 \mathrm{~s}$.

\section{Transmission electron microscopy (TEM)}


Lungs, livers, and kidneys were cut into approximately $1 \mathrm{~mm}^{3}$ samples. Tissue samples were fixed in $3 \%$ glutaraldehyde for $24 \mathrm{~h}$, rinsed in $0.1 \mathrm{M}$ cacodylate buffer (minimally three times), and post-fixed in $1 \%$ $\mathrm{OsO}_{4}$ solution for $1.5 \mathrm{~h}$ at RT. After washing in cacodylate buffer, all samples were dehydrated in a series of ascending concentrations of ethanol, followed by acetone. The samples were embedded in the epoxy resin Durcupan ACM, followed by polymerisation for three days at $60-80^{\circ} \mathrm{C}$. From selected parts of the samples, ultrathin sections ( $60 \mathrm{~nm}$ thick) were prepared for TEM analysis. The sections were cut using an ultramicrotome Leica EM UC6 (Leica Microsystem GmbH, Vienna, Austria) and collected on formvarcoated nickel grids.

Some sections were without following contrast to study nanoparticles in electron microscopy. The additional sections were contrasted with uranyl citrate and lead acetate to visualise the histopathological alterations of tissues. All sections were examined using Morgagni ${ }^{\text {TM }} 268$ TEM (FEI Company, Eindhoven, Netherlands), working at $90 \mathrm{kV}$ and equipped with a Veleta $C C D$ camera (Olympus, Münster, Germany) for taking photographs. The designated structures were measured using iTEM software.

\section{Scanning electron microscopy (SEM)/Energy-dispersive X- ray spectroscopy (EDS)}

For SEM/EDS analysis in transmission mode, ultrathin sections of liver tissue were directly deposited on the nickel grids without post-section staining. The grids were placed on an aluminium holder and analysed with SEM TESCAN MAIA3 (Tescan, Brno, Czech Republic) using $30 \mathrm{keV}$ landing energy, equipped with an EDS detector (X-Max Extreme, Oxford Instruments).

\section{Determination of lead in mouse organs}

In the analysis of organs, the weights of individual organs were determined, and the values were recorded for later quantitative evaluation. The individual organs were decomposed by microwave (MW) assisted digestion in $3 \mathrm{~mL}$ of concentrated subboil grade nitric acid (quartz distillation system model MSBQ 2 , Maasen, Eningen, Germany). The samples were treated in pre-cleaned quartz tubes of a closed pressurised autoclave system (UltraWave, Milestone s.r.l., Italy). The decomposition program consisted of four steps: 1 st step - 10 min with temperature ramp between 100 and $120^{\circ} \mathrm{C}$; 2 nd step -5 min with temperature ramp between 120 and $200^{\circ} \mathrm{C}$; 3rd step - 3 min with temperature ramp between 200 and $250^{\circ} \mathrm{C}$; and 4 th step $-5 \mathrm{~min}$ at $250^{\circ} \mathrm{C}$. After cooling down (a duration of approx. $10 \mathrm{~min}$ ), digests were quantitatively transferred to high-density polyethene vials, diluted, and adjusted with ultrapure water (Ultra Clear system, SB Barsbüttel, Germany) to the final mass of $10 \mathrm{~g}$. Simultaneously, blank samples (typically $n=12$ per sampling series) were processed analogously.

The content of lead in the digests was determined by electrothermal atomic absorption spectrometry (ET AAS), employing AAnalyst 600 PerkinElmer (USA) instrumentation under recommended conditions. A mixture of ammonium phosphate and magnesium nitrate was used as a combined chemical modifier. The method of standard addition calibration was applied for quantitation.

\section{Statistical analyses}


Statistical analyses were performed with GraphPad Prism 5 (GraphPad Software, Inc., La Jolla, CA, USA). Unpaired Student's t-tests were used to determine differences between PbO NP and control groups.

Results were reported as the mean value \pm standard deviation. Values of $p<0.05$ were considered to be statistically significant.

\section{Declarations}

\section{Ethics approval and consent to participate}

The experiment was approved by the Ethical Board of the Institute of Analytical Chemistry, v.v.i., Czech Academy of Sciences, Brno (Approval No. 64/2016, 15 August 2016).

\section{Consent for publication}

The manuscript as submitted has been read and approved by all authors.

\section{Availability of data and Material}

This manuscript has not been submitted simultaneously for publication in any other journal, nor have the findings been partially disclosed in any other publication.

\section{Competing interests}

The authors declared that there is no conflict of interest.

\section{Funding}

The work was supported by the Czech Science Foundation (grant no. 20-02203S).

\section{Author's contributions}

PM, MB: conceived and designed experiments

TS, DK, LV, BD, PM, LA, AJ, ZV, KK, PC, DV: performed experiments

TS, JD, SZ, MB, PC: analyzed the data

$\mathrm{PM}, \mathrm{AH}, \mathrm{MB}$ : contributed reagents and materials

TS, JD, PM, AH, MB: wrote the paper

\section{Acknowledgements}

Authors would like to thank Dobromila Klemová for help with the processing of TEM samples and Daniela Dumková for the assistance and advice on the graphic editing. 
Supplementary Materials: Supplementary Materials can be found at ......

\section{References}

1. Maynard AD. Nanotechnology: assessing the risks. Nano Today. 2006;1 2:22-33. doi:10.1016/s1748-0132(06)70045-7.

2. Papanikolaou NC, Hatzidaki EG, Belivanis S, Tzanakakis GN, Tsatsakis AM. Lead toxicity update. A brief review. Medical science monitor. 2005;11 10:RA329-6.

3. Li QZ, Hu XL, Bai YP, Alattar M, Ma D, Cao YH, et al. The oxidative damage and inflammatory response induced by lead sulfide nanoparticles in rat lung. Food and Chemical Toxicology. 2013;60:213-7; doi: 10.1016/j.fct.2013.07.046. <Go to ISI>://WOS:000325231700026.

4. Zhao Y, Zhang Z, Dang H. Fabrication and tribological properties of Pb nanoparticles. J Nanopart Res. 2004;6(1):47-51.

5. Bláhová L, Nováková Z, Večeřa Z, Vrlíková L, Dočekal B, Dumková J, et al. The effects of nano-sized $\mathrm{PbO}$ on biomarkers of membrane disruption and DNA damage in a sub-chronic inhalation study on mice. Nanotoxicology. 2019:1-18.

6. Dumková J, Smutná T, Vrlíková L, Kotasová H, Dočekal B, Čapka L, et al. Variability in the Clearance of Lead Oxide Nanoparticles Is Associated with Alteration of Specific Membrane Transporters. ACS Nano. 2020;14(3):3096-120.

7. Dumková J, Smutná T, Vrlíková L, Le Coustumer P, Večeřa Z, Dočekal B, et al. Sub-chronic inhalation of lead oxide nanoparticles revealed their broad distribution and tissue-specific subcellular localization in target organs. Particle Fibre Toxicology. 2017;14 1:55; doi:10.1186/s12989-017-0236y.

8. Dukhinova MS, Prilepskii A, Shtil AA, Vinogradov VV. Metal oxide nanoparticles in therapeutic regulation of macrophage functions. Nanomaterials. 2019;9 11:1631.

9. Zhu L, Jones C, Zhang G. The role of phospholipase C signaling in macrophage-mediated inflammatory response. Journal of immunology research. 2018;2018.

10. Aleksiichuk V, Omelchuk S, Sokurenko L, Kaminsky R, Kovalchuk O, Chaikovsky Y. The influence of lead nanoparticles on the morpho-functional changes of rat liver during the postexposure period. Microscopy research technique. 2018;81 7:781-8.

11. Nassir F, Rector RS, Hammoud GM, Ibdah JA. Pathogenesis and prevention of hepatic steatosis. Gastroenterology hepatology. 2015;11 3:167.

12. Zhang J, Wang Y, Fu L, Feng YJ, Ji YL, Wang H, et al. Subchronic cadmium exposure upregulates the mRNA level of genes associated to hepatic lipid metabolism in adult female CD1 mice. J Appl Toxicol. 2018;38 7:1026-35.

13. Casals E, Vazquez-Campos S, Bastus N, Puntes V. Distribution and potential toxicity of engineered inorganic nanoparticles and carbon nanostructures in biological systems. Trac-Trends in Analytical Chemistry 2008;27; doi:10.1016/j.trac.2008.06.004. 
14. Labouta $\mathrm{HI}$, Schneider M. Interaction of inorganic nanoparticles with the skin barrier: current status and critical review. Nanomed Nanotechnol Biol Med. 2013;9 1:39-54.

15. Casals E, Pfaller T, Duschl A, Oostingh G, Puntes V. Time Evolution of the Nanoparticle Protein Corona. Acs Nano. 2010;4 7:3623-32. doi:10.1021/nn901372t.

16. Bide RW, Armour SJ, Yee E. Allometric respiration/body mass data for animals to be used for estimates of inhalation toxicity to young adult humans. J Appl Toxicol. 2000;20(4):273-90.

17. Miller FJ. Dosimetry of particles in laboratory animals and humans in relationship to issues surrounding lung overload and human health risk assessment: a critical review. Inhal Toxicol. 2000;12(1-2):19-57. doi:10.1080/089583700196329.

18. Mitchell LA, Gao J, Wal RV, Gigliotti A, Burchiel SW, McDonald JD. Pulmonary and systemic immune response to inhaled multiwalled carbon nanotubes. Toxicol Sci. 2007;100(1):203-14. doi:10.1093/toxsci/kfm196.

19. De Winter-Sorkina R, Cassee F. From concentration to dose: factors influencing airborne particulate matter deposition in humans and rats. 2003.

20. MPPD. Multiple-Path Particle Dosimetry Model. https:// Accessed November 102020.

21. Dumková J, Smutná T, Vrlíková L, Le Coustumer P, Večeřa Z, Dočekal B, et al. Sub-chronic inhalation of lead oxide nanoparticles revealed their broad distribution and tissue-specific subcellular localization in target organs. Part Fibre Toxicol. 2017;14 1:55; doi:10.1186/s12989-017-0236-y.

22. Reyes NJ, O'Koren EG, Saban DR. New insights into mononuclear phagocyte biology from the visual system. Nat Rev Immunol. 2017;17 5:322.

23. Nakamura Y, Fukami K. Regulation and physiological functions of mammalian phospholipase C. The Journal of Biochemistry. 2017;161:4:315-21.

24. Kudo K, Uchida T, Sawada M, Nakamura Y, Yoneda A, Fukami K. Phospholipase $C \delta 1$ in macrophages negatively regulates TLR4-induced proinflammatory cytokine production and Fcy receptor-mediated phagocytosis. Advances in Biological Regulation. 2016;61:68-79.

25. Chistiakov DA, Bobryshev YV, Orekhov AN. Macrophage-mediated cholesterol handling in atherosclerosis. J Cell Mol Med. 2016;20(1):17-28.

26. Dumkova J, Vrlikova L, Vecera Z, Putnova B, Docekal B, Mikuska P, et al. Inhaled Cadmium Oxide Nanoparticles: Their in Vivo Fate and Effect on Target Organs. Int J Mol Sci 2016;17 6; doi:10.3390/ijms17060874.

27. Lebedova J, Blahova L, Vecera Z, Mikuska P, Docekal B, Buchtova M, et al. Impact of acute and chronic inhalation exposure to CdO nanoparticles on mice. Environ Sci Pollut Res. 2016;23 23:24047-60. doi:10.1007/s11356-016-7600-6.

28. Krenkel O, Tacke F. Liver macrophages in tissue homeostasis and disease. Nat Rev Immunol. 2017;17:5:306-21.

29. lancu TC. Ultrastructural aspects of iron storage, transport and metabolism. J Neural Transm. 2011;118:3:329-35. 
30. Daley GM, Pretorius CJ, Ungerer JP. Lead Toxicity: an Australian Perspective. The Clinical Biochemist Reviews. 2018;39 4:61.

31. Nowack B, Bucheli TD. Occurrence, behavior and effects of nanoparticles in the environment. Environmental pollution. 2007;150 1:5-22.

32. Huang H, Polavarapu L, Sichert JA, Susha AS, Urban AS, Rogach AL. Colloidal lead halide perovskite nanocrystals: synthesis, optical properties and applications. NPG Asia Materials. 2016;8 11:e328-e.

33. Elango G, Roopan SM. Green synthesis, spectroscopic investigation and photocatalytic activity of lead nanoparticles. Spectrochim Acta Part A Mol Biomol Spectrosc. 2015;139:367-73.

34. Bratovcic A. Synthesis, characterization, applications, and toxicity of lead oxide nanoparticles. Lead Chemistry: IntechOpen; 2020.

35. Blum JL, Rosenblum LK, Grunig G, Beasley MB, Xiong JQ, Zelikoff JT. Short-term inhalation of cadmium oxide nanoparticles alters pulmonary dynamics associated with lung injury, inflammation, and repair in a mouse model. Inhal Toxicol. 2014;26(1):48-58. doi:10.3109/08958378.2013.851746.

36. Takenaka S, Karg E, Kreyling WG, Lentner B, Schulz H, Ziesenis A, et al. Fate and toxic effects of inhaled ultrafine cadmium oxide particles in the rat lung. Inhal Toxicol. 2004;16(Suppl 1):83-92. doi:10.1080/08958370490443141.

37. Lee S, Choi J, Shin S, Im YM, Song J, Kang SS, et al. Analysis on migration and activation of live macrophages on transparent flat and nanostructured titanium. Acta Biomater 2011;7; doi:10.1016/j.actbio.2011.01.006.

38. Blum JL, Xiong JQ, Hoffman C, Zelikoff JT. Cadmium associated with inhaled cadmium oxide Nanoparticles impacts fetal and neonatal development and growth. Toxicol Sci 2012;126; doi:10.1093/toxsci/kfs008.

39. Kreyling WG, Semmler-Behnke M, Seitz J, Scymczak W, Wenk A, Mayer P, et al. Size dependence of the translocation of inhaled iridium and carbon nanoparticle aggregates from the lung of rats to the blood and secondary target organs. Inhal Toxicol. 2009;21; doi:10.1080/08958370902942517.

40. Pietroiusti A, Bergamaschi E, Campagna M, Campagnolo L, De Palma G, lavicoli S, et al. The unrecognized occupational relevance of the interaction between engineered nanomaterials and the gastro-intestinal tract: a consensus paper from a multidisciplinary working group. Part Fibre Toxicol. 2017;14 1:47; doi:10.1186/s12989-017-0226-0.

41. Togao M, Nakayama SM, Ikenaka Y, Mizukawa H, Makino Y, Kubota A, et al. Bioimaging of Pb and STIM1 in mice liver, kidney and brain using Laser Ablation Inductively Coupled Plasma Mass Spectrometry (LA-ICP-MS) and immunohistochemistry. Chemosphere. 2020;238:124581.

42. Ivanova J, Gluhcheva Y, Dimova D, Pavlova E, Arpadjan S. Comparative assessment of the effects of salinomycin and monensin on the biodistribution of lead and some essential metal ions in mice, subjected to subacute lead intoxication. Journal of Trace Elements in Medicine Biology. 2016;33:316.

43. Lebedova J, Novakova Z, Vecera Z, Buchtova M, Dumkova J, Docekal B, et al. Impact of acute and subchronic inhalation exposure to PbO nanoparticles on mice. Nanotoxicology. 2018;12 4:290-304. 
doi:10.1080/17435390.2018.1438679.

44. Oszlanczi G, Papp A, Szabo A, Nagymajtenyi L, Sapi A, Konya Z, et al. Nervous system effects in rats on subacute exposure by lead-containing nanoparticles via the airways. Inhalation Toxicol. 2011;23 4:173-81. doi:10.3109/08958378.2011.553248.

45. Makhdoumi P, Karimi H, Khazaei M. Review on Metal-Based Nanoparticles: Role of Reactive Oxygen Species in Renal Toxicity. Chem Res Toxicol. 2020;33 10:2503-14.

46. Minigalieva IA, Katsnelson BA, Panov VG, Privalova LI, Varaksin AN, Gurvich VB, et al. In vivo toxicity of copper oxide, lead oxide and zinc oxide nanoparticles acting in different combinations and its attenuation with a complex of innocuous bio-protectors. Toxicology. 2017;380:72-93.

47. Cho WS, Duffin R, Poland CA, Howie SE, MacNee W, Bradley M, et al. Metal oxide nanoparticles induce unique inflammatory footprints in the lung: important implications for nanoparticle testing. Environ Health Perspect. 2010;118 12:1699-706. doi:10.1289/ehp.1002201.

48. Dumková J, Smutná T, Vrlíková L, Dočekal B, Kristeková D, Večeřa Z, et al. A clearance period after soluble lead nanoparticle inhalation did not ameliorate the negative effects on target tissues due to decreased immune response. Int J Mol Sci. 2020;21 22:8738.

49. Cho WS, Duffin R, Poland CA, Duschl A, Oostingh GJ, Macnee W, et al. Differential pro-inflammatory effects of metal oxide nanoparticles and their soluble ions in vitro and in vivo; zinc and copper nanoparticles, but not their ions, recruit eosinophils to the lungs. Nanotoxicology 2012;6; doi:10.3109/17435390.2011.552810.

50. Muehlfeld C, Gehr P, Rothen-Rutishauser B. Translocation and cellular entering mechanisms of nanoparticles in the respiratory tract. Swiss Medical Weekly. 2008;138 27-28:387 - 91. <Go to ISI>://WOS:000257686400001.

51. Nemmar A, Melghit K, Ali BH. The acute proinflammatory and prothrombotic effects of pulmonary exposure to rutile TiO2 nanorods in rats. Exp Biol Med (Maywood). 2008;233 5:610-9. doi:10.3181/0706-RM-165.

52. Russell DG, Cardona P-J, Kim M-J, Allain S, Altare F. Foamy macrophages and the progression of the human tuberculosis granuloma. Nature immunology. 2009;10 9:943-8.

53. Yuan Y, Li P, Ye J. Lipid homeostasis and the formation of macrophage-derived foam cells in atherosclerosis. Protein cell. 2012;3(3):173-81.

54. Gibeon D, Zhu J, Sogbesan A, Banya W, Rossios C, Saito J, et al. Lipid-laden bronchoalveolar macrophages in asthma and chronic cough. Respiratory medicine. 2014;108(1):71-7.

55. Peyron P, Vaubourgeix J, Poquet Y, Levillain F, Botanch C, Bardou F, et al. Foamy macrophages from tuberculous patients' granulomas constitute a nutrient-rich reservoir for M. tuberculosis persistence. PLoS Pathog. 2008;4 11:e1000204.

56. Bae Y-S, Lee HY, Jung YS, Lee M, Suh P-G. Phospholipase Cy in Toll-like receptor-mediated inflammation and innate immunity. Advances in biological regulation. 2017;63:92-7.

57. Nalabotu SK, Kolli MB, Triest WE, Ma JY, Manne NDPK, Katta A, et al. Intratracheal instillation of cerium oxide nanoparticles induces hepatic toxicity in male Sprague-Dawley rats. Int J 
Nanomedicine 2011;6; doi:10.2147/IJN.S25119.

58. Jarrar BM, Taib NT. Histological and histochemical alterations in the liver induced by lead chronic toxicity. Saudi journal of biological sciences. 2012;19(2):203-10.

59. Thoolen B, Maronpot RR, Harada T, Nyska A, Rousseaux C, Nolte T, et al. Proliferative and nonproliferative lesions of the rat and mouse hepatobiliary system. Toxicol Pathol. 2010;38 7 Suppl:5S-81S; doi:10.1177/0192623310386499. https://www.ncbi.nlm.nih.gov/pubmed/21191096.

60. Scudamore CL. Gastrointestinal system. A Practical Guide to the Histology of the Mouse. John Wiley \& Sons, Ltd.; 2014. pp. 43-61.

61. Zani IA, Stephen SL, Mughal NA, Russell D, Homer-Vanniasinkam S, Wheatcroft SB, et al. Scavenger receptor structure and function in health and disease. Cells. 2015;4 2:178-201.

62. Shen W-J, Azhar S, Kraemer FB. SR-B1: a unique multifunctional receptor for cholesterol influx and efflux. Annu Rev Physiol. 2018;80:95-116.

63. Endemann G, Stanton L, Madden KS, Bryant CM, White RT, Protter AA. CD36 is a receptor for oxidized low density lipoprotein. J Biol Chem. 1993;268 16:11811-6.

64. De Villiers WJ, Smart EJ. Macrophage scavenger receptors and foam cell formation. J Leukoc Biol. 1999;66 5:740-6.

65. Moore KJ, Freeman MW. Scavenger receptors in atherosclerosis: beyond lipid uptake. Arteriosclerosis, thrombosis, and vascular biology. 2006;26 8:1702-11.

66. Febbraio M, Hajjar DP, Silverstein RL. CD36: a class B scavenger receptor involved in angiogenesis, atherosclerosis, inflammation, and lipid metabolism. J Clin Investig. 2001;108(6):785-91.

67. Suzuki Y, Tada-Oikawa S, Ichihara G, Yabata M, Izuoka K, Suzuki M, et al. Zinc oxide nanoparticles induce migration and adhesion of monocytes to endothelial cells and accelerate foam cell formation. Toxicol Appl Pharmcol. 2014;278(1):16-25.

68. Broeg K, Westernhagen HV, Zander S, Körting W, Koehler A. The "bioeffect assessment index" (BAI). A concept for the quantification of effects of marine pollution by an integrated biomarker approach. Mar Pollut Bull. 2005;50 5:495-503. doi:10.1016/j.marpolbul.2005.02.042.

69. Shannahan JH, Sowrirajan H, Persaud I, Podila R, Brown JM. Impact of silver and iron nanoparticle exposure on cholesterol uptake by macrophages. Journal of nanomaterials. 2015;2015.

70. Kou H, Ya J, Gao X, Zhao H. The effects of chronic lead exposure on the liver of female Japanese quail (Coturnix japonica): Histopathological damages, oxidative stress and AMP-activated protein kinase based lipid metabolism disorder. Ecotoxicol Environ Saf. 2020;190:110055.

71. Loghman-Adham M. Aminoaciduria and glycosuria following severe childhood lead poisoning. Pediatric nephrology. 1998;12(3):218-21.

72. Lim AK. Diabetic nephropathy-complications and treatment. International journal of nephrology renovascular disease. 2014;7:361.

73. Dias CB, Malafronte P, Lee J, Resende A, Jorge L, Pinheiro CC, et al. Role of renal expression of CD68 in the long-term prognosis of proliferative lupus nephritis. J Nephrol. 2017;30(1):87-94. 
74. Marks SD, Williams SJ, Tullus K, Sebire NJ. Glomerular expression of monocyte chemoattractant protein-1 is predictive of poor renal prognosis in paediatric lupus nephritis. Nephrology Dialysis Transplantation. 2008;23 11:3521-6.

75. Rovin BH, Rumancik M, Tan L, Dickerson J. Glomerular expression of monocyte chemoattractant protein-1 in experimental and human glomerulonephritis. Lab Invest. 1994;71(4):536-42.

76. Zhang $X$, Yang $Y$, Zhao Y. Macrophage phenotype and its relationship with renal function in human diabetic nephropathy. PloS one. 2019;14 9:e0221991.

77. Večeřa Z, Mikuška P, Moravec P, Smolík J. Unique exposure system for the whole body inhalation experiments with small animals. Brno: TANGER Ltd NANOCON; 2011. pp. 652-4.

\section{Figures}
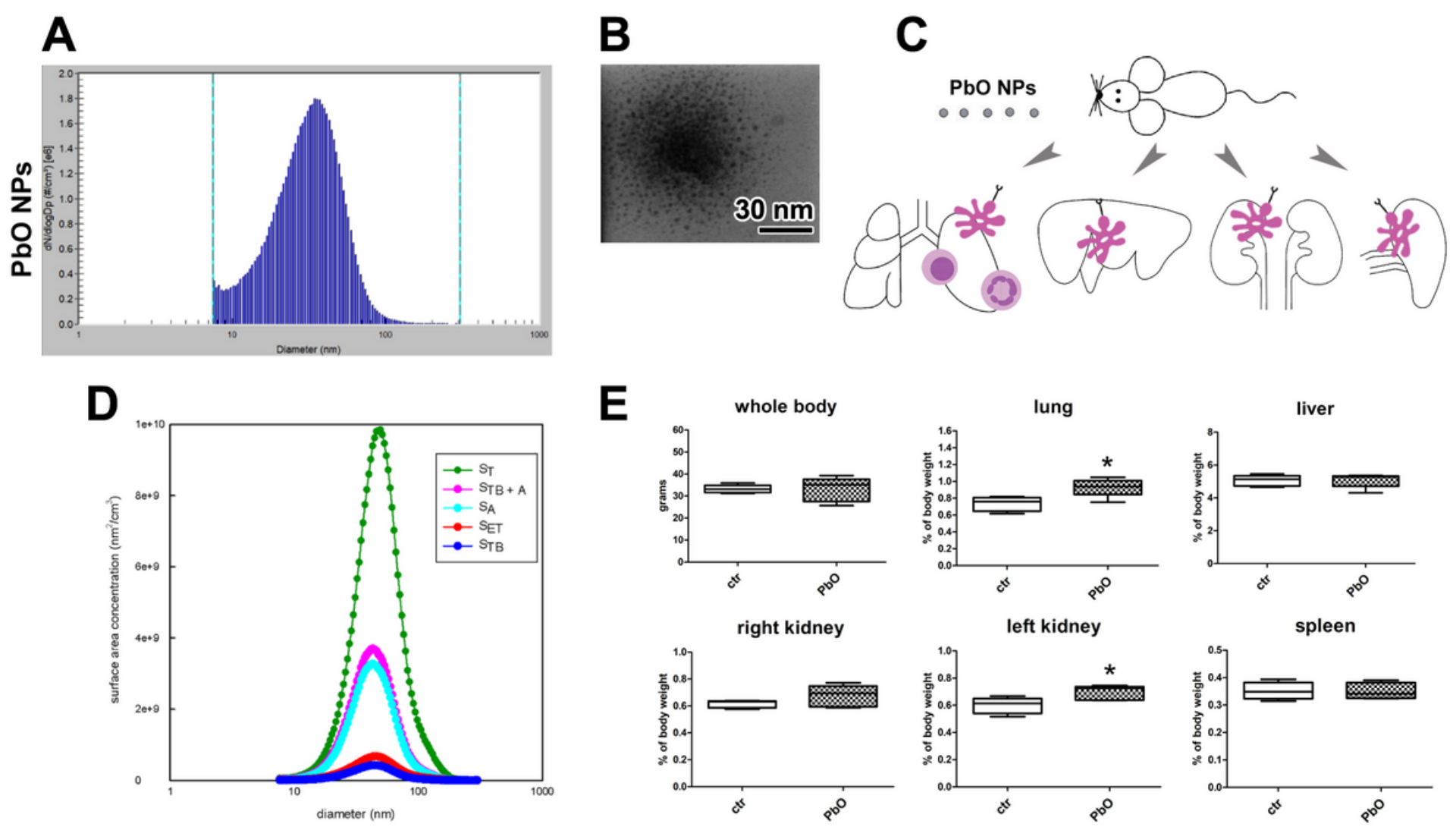

\section{Figure 1}

Characterization of PbO NPs. A) Particle count concentration of PbO NPs in the inhalation chambers measured by Scanning Mobility Particle Sizer (SMPS). B) STEM image of PbO NPs. C) Design of the inhalation experiment. D) Surface area of PbO NP size distribution (dS/dlogDp). The surface area of fractions of PbO NPs deposited in the extrathoracic (SET), tracheobronchiolar (STB) and alveolar region (SA) of lungs, ST - the total surface area of generated PbO NPs, STB + A - the lung-deposited surface area. E) Analysis of weight of target organs after exposure to PbO NPs. The graphs values denote average $\pm S D ; * p<0.05$ by unpaired t-test. 

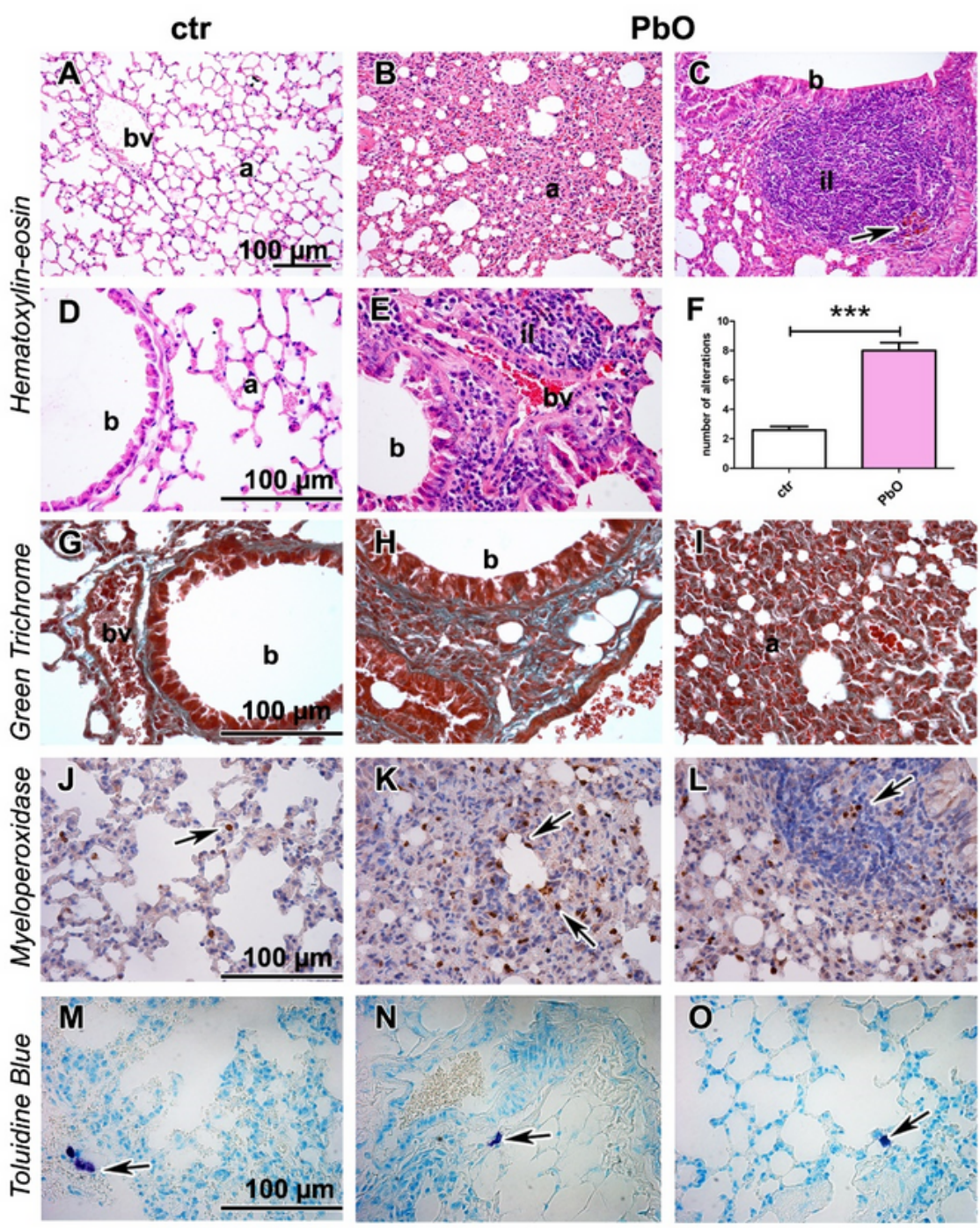

\section{$\mathrm{PbO}$}
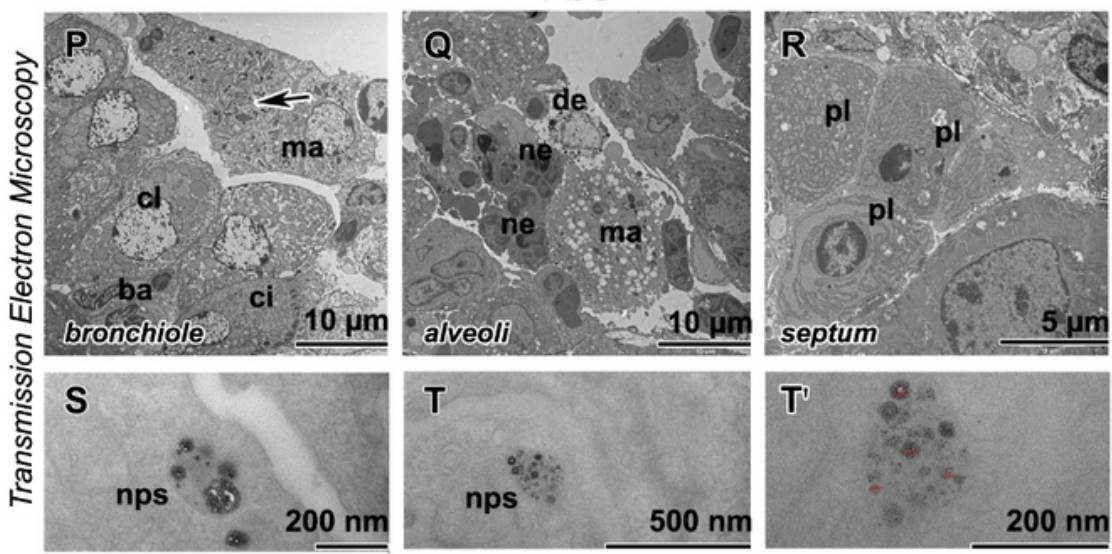

\section{Figure 2}

Lung after 11-week PbO NP inhalation. A, D) Lungs in control animals without alternations. B, C, E) Exposure to PbO NPs caused remodeling of lung tissue in alveolar areas (a). There are peribronchiolar (b) or perivascular (bv) inflammatory infiltrates of leukocytes (il) after PbO NPs inhalation. Arrow shows hemosiderin. F) Statistical evaluation of histopathological changes after 11 weeks of lead oxide nanoparticle inhalation according to the Table S1. The graphs values denote average \pm SD; $* \star \star ~ p<0.001$ 
by unpaired t-test. G-I) Amount of collagen fibres (green) is not changed after inhalation of PbO NPs. Collagen fibers are around blood vessels (bv) and bronchioles (b). There are not any collagen fibers in alveolar areas despite serious remodeling. J-L) MPO detection in lung tissue. Arrows display myeloperoxidase-positive cells - neutrophils. M-0) Mastocytes (arrows) in lungs. Scale bar in all panels = $100 \mu \mathrm{m}$. P-R) The ultrastructural morphology of the lung tissue with inflammatory features. P) Terminal bronchiole lined with secretory club (cl), basal (ba) and ciliated (ci) cells; macrophage (ma) with cholesterol crystals inside (arrow) the lumen. Q) Numerous macrophages (ma), neutrophils (ne) and abundant cell debris (de) in lung alveoli. R) Clump of plasma cells ( $\mathrm{pl}$ ) around vessel in alveolar septum. $\mathrm{S}, \mathrm{T}, \mathrm{T}^{\prime}$ ) Endosomes with $\mathrm{PbO}$ nanoparticles (nps) in pneumocyte type I. Scale bars are displayed individually for each picture.
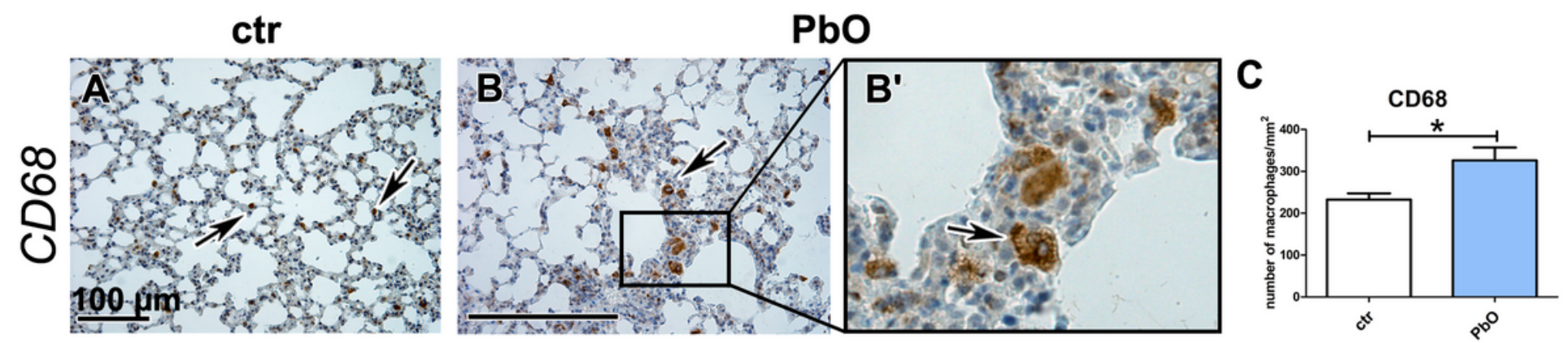

D
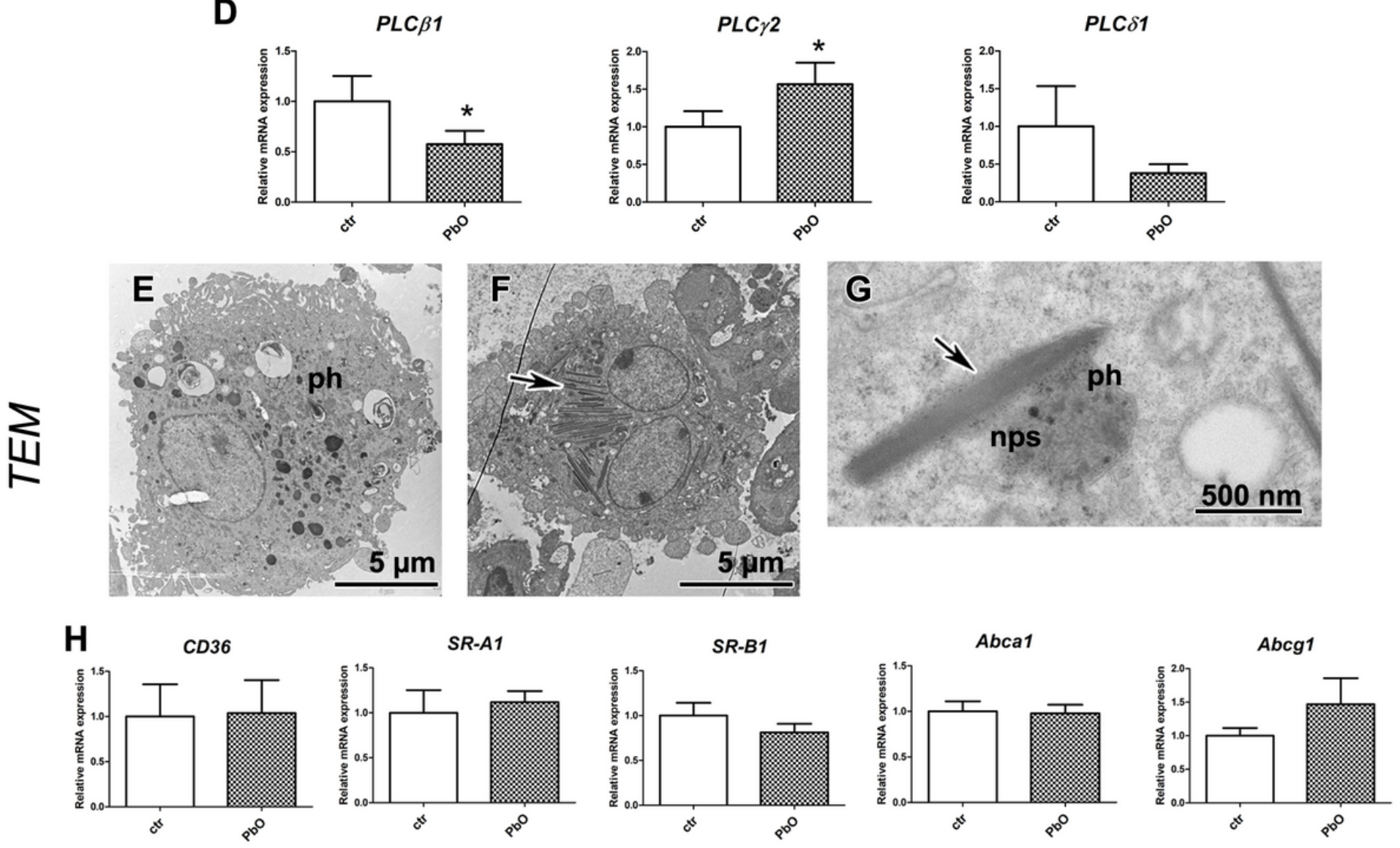

Figure 3 
Lung macrophages after 11-week PbO NP inhalation. A, B) Detection of CD68-positive cells (marker of macrophages) in lungs (arrows). Scale bar in panels $=100 \mu \mathrm{m}$. C) The number of macrophages was significantly increased compared with the control group (the graphs values indicate average $\pm S D$; $p<$ 0.05). D) Gene expression of phospholipases $C$ after $\mathrm{PbO}$ NP inhalation. The graphs values indicate average $\pm S D ; * ~ p<0.05$ compared with the corresponding control group (ctr) by unpaired t-test. E, F) TEM images of foam alveolar macrophages with phagosomes (ph) in PbO NP group of animals. Arrow indicates cholesterol crystals in cytoplasm of macrophage. G) Close interaction between phagosome (ph) with nanoparticles (nps) and cholesterol crystal (arrow). Scale bars are displayed individually for each picture. H) Gene expression of receptors CD36, SR-A1, SR-B1, Abca1 and Abcg1 after Pb0 NP inhalation. The graphs values indicate average \pm SD. 

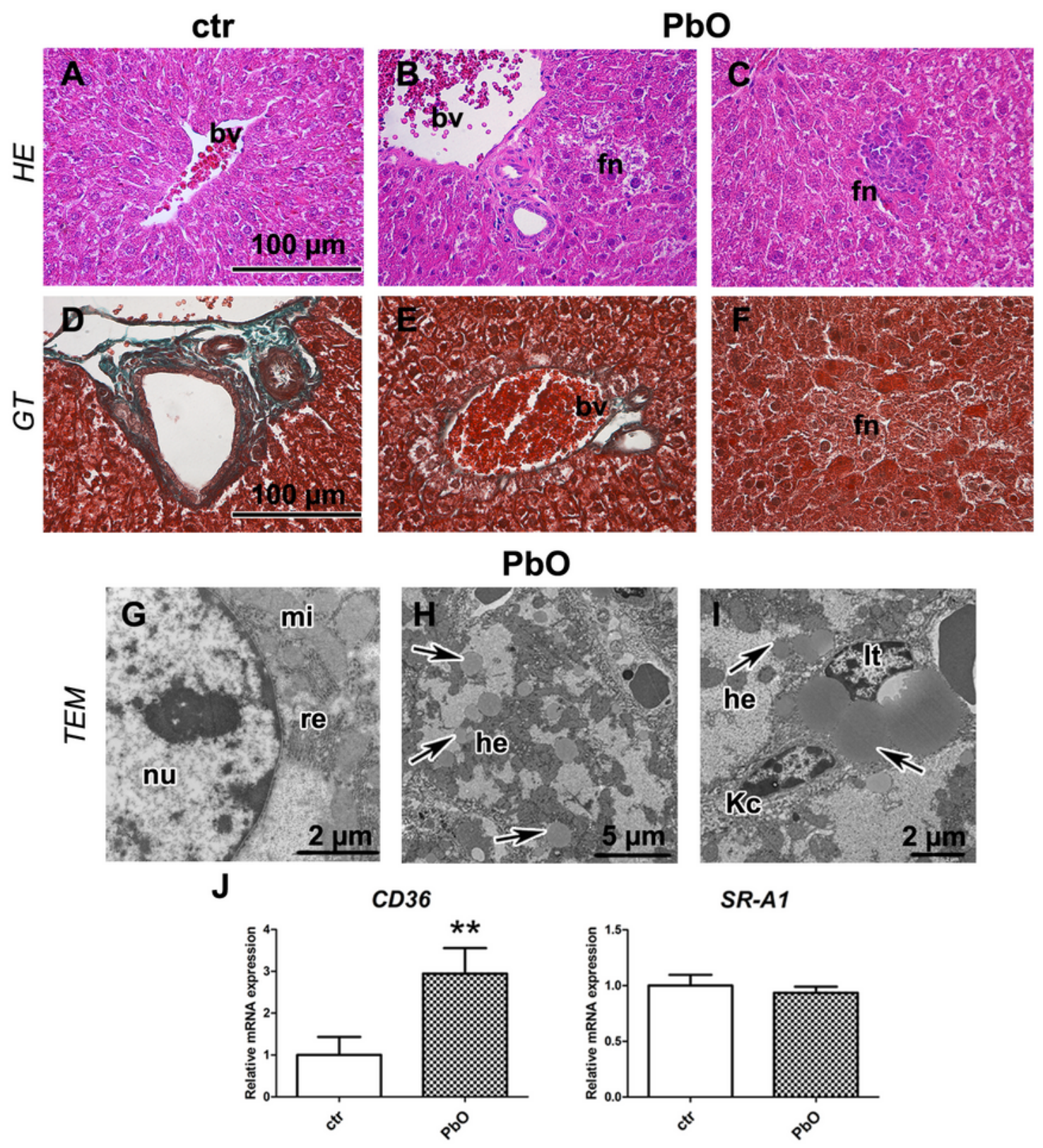

$\mathrm{PbO}$

$S R-B 1$

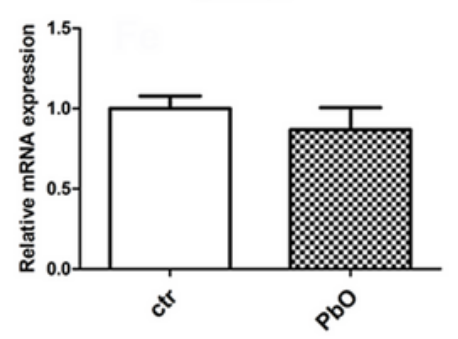

Abca1

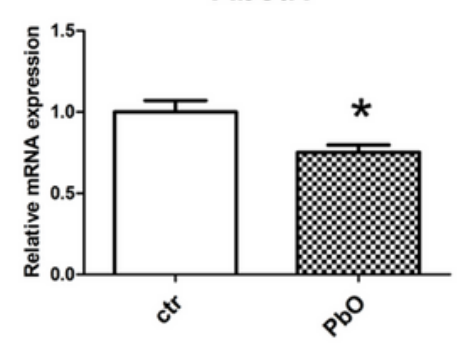

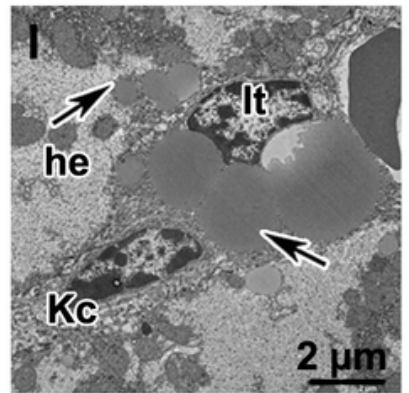

$S R-A 1$

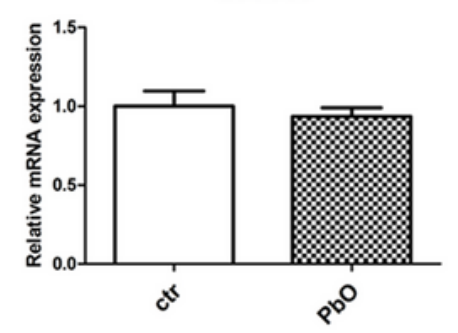

Abcg1

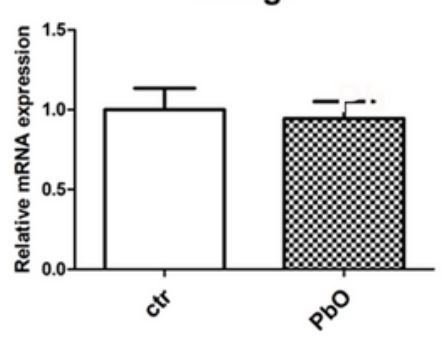

\section{Figure 4}

Liver after 11-week PbO NP inhalation. A) Liver in control animals (HE staining); bv blood vessels. B, C) Liver of PbO NPs treated animals exhibited remodeling of tissue and focal necrosis (fn). D-F) Collagen fibers (green) in liver are around blood vessel (bv) in both groups (GT staining). There is no presence of fibrosis in focal necrosis (fn). Scale bar in all panels $=100 \mu \mathrm{m} . \mathrm{G}, \mathrm{H}$ ) TEM images of hepatocytes (he) with lipid droplets (arrows), Ito cell (It) with lipid droplets (arrow), and Kupffer cell (Kc). Scale bars are 
displayed individually for each picture. I, J) Gene expression of receptors CD36, SR-A1, SR-B1, Abca1 and Abcg1 after PbO NP inhalation. The graphs values indicate average $\pm S D ; * p<0.05, * \star p<0.01$ by unpaired t-test.
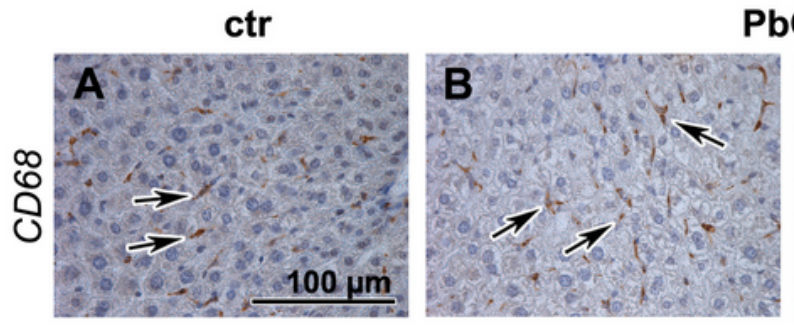

$\mathrm{PbO}$
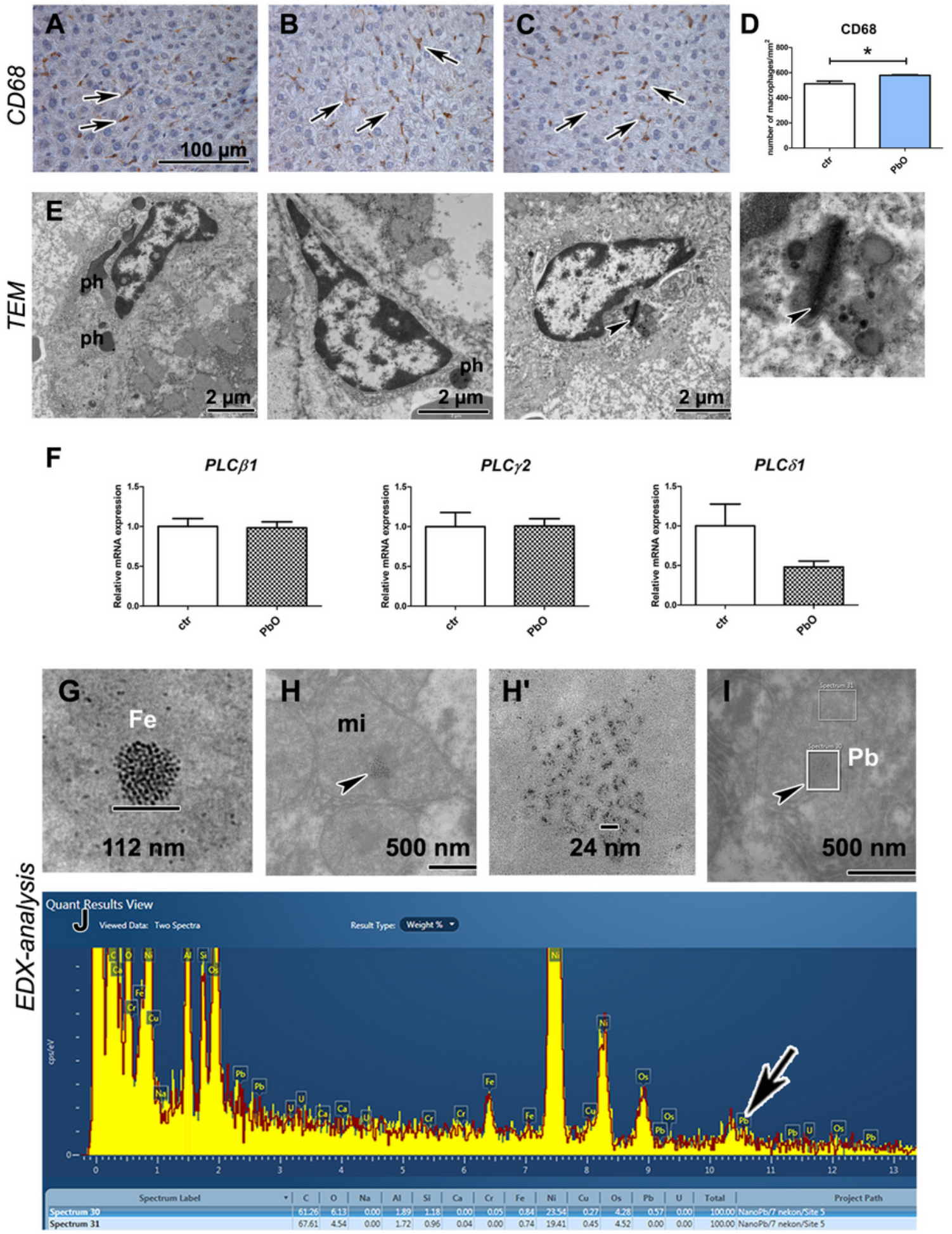

Figure 5

Liver macrophages after 11-week PbO NP inhalation. A-C) Detection of CD68-positive cells (marker of macrophages) in liver (arrows). Scale bar in panels $=100 \mu \mathrm{m}$. D) The number of macrophages was 
significantly increased compared with the control group (the graphs values indicate average $\pm S D$; * $p<$ 0.05). E) Kupffer cells with phagosomes (ph). Arrowheads display cholesterol crystal in Kupffer cell. Scale bar in panels $=2 \mu \mathrm{m}$. F) Gene expression of phospholipases $\mathrm{C}$ after PbO NP inhalation. The graphs values indicate average \pm SD. G) Ferritin agglomerate (sized $112 \mathrm{~nm}$ ). H) Hepatocyte mitochondria (mi) with agglomerates of $\mathrm{PbO}$ nanoparticles (arrowheads) surrounded with electrondense matrix. $\mathrm{H}^{\prime}$ ) Detail of agglomerates of $\mathrm{PbO}$ nanoparticles (size range $10-40 \mathrm{~nm}$ ). I, J) SEM in transmission mode, using TESCAN RSTEM detector, and energy-dispersive X-ray spectroscopy (X-EDS) of lead treated samples of liver. Data obtained from two ROI windows analyzed inside hepatocyte mitochondria ( $\mathrm{I}$ - with and without NPs). Spectra were compared with a reference sample and analyzed using Oxford AZtec. Presence of $\mathrm{Pb}$ was confirmed by comparing reference Spectrum 31 (without NPs) and non-reference Spectrum 30 (with NPs, arrowhead on image I). The peak displays increased signal at a spectral position of $\mathrm{Pb}$ (arrow on graph J). Nickel was observed during analysis as it was issued from the grid and osmium from postfixation. 


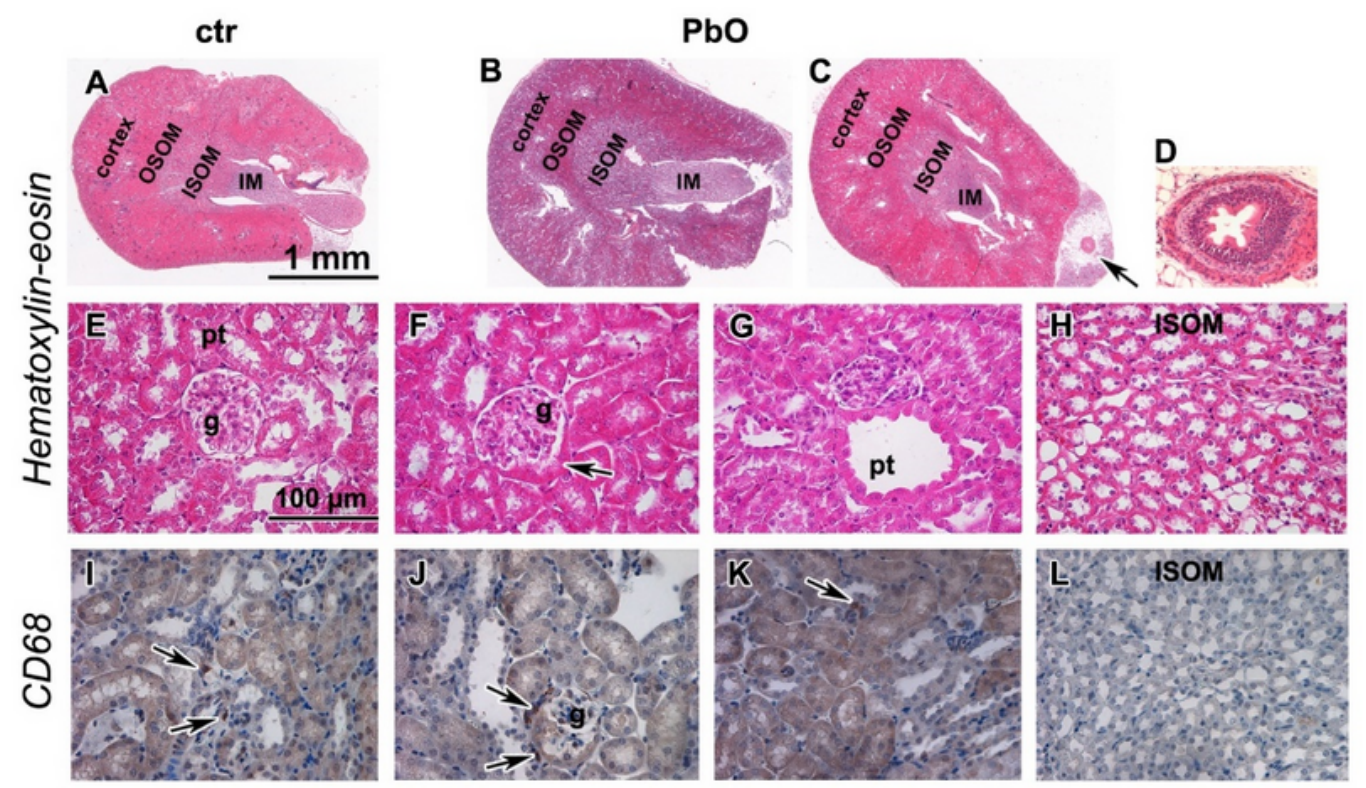

$\mathrm{PbO}$
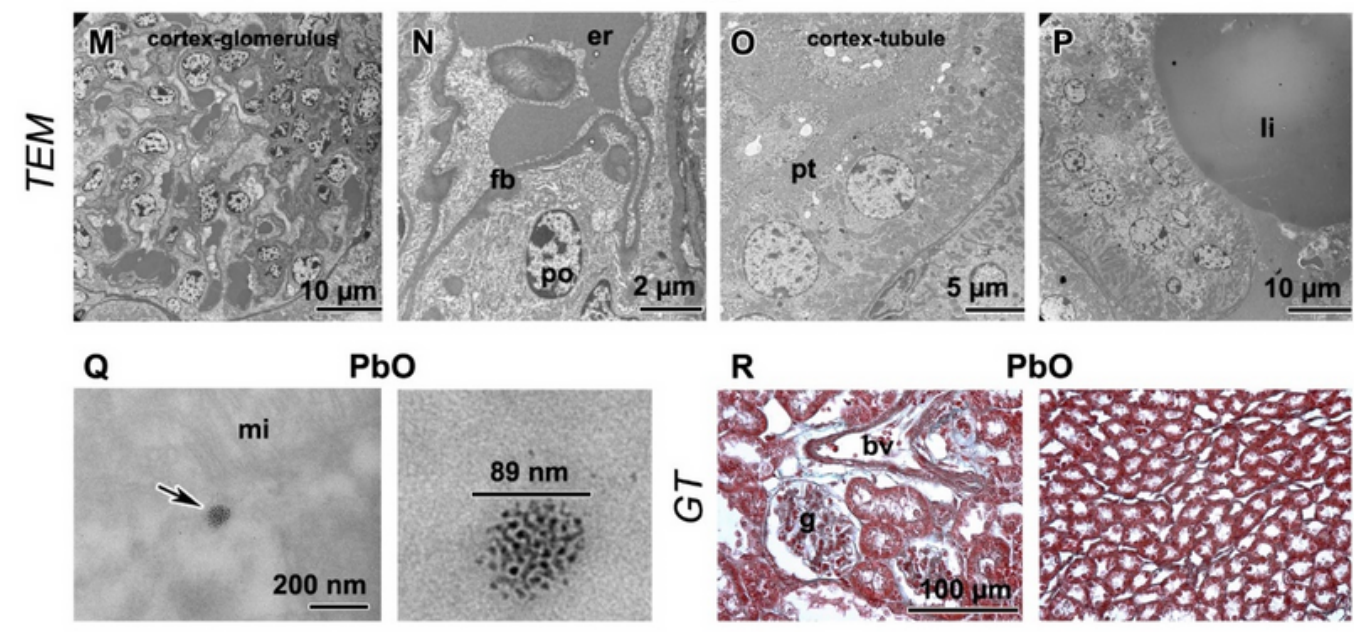

$\mathrm{PbO}$
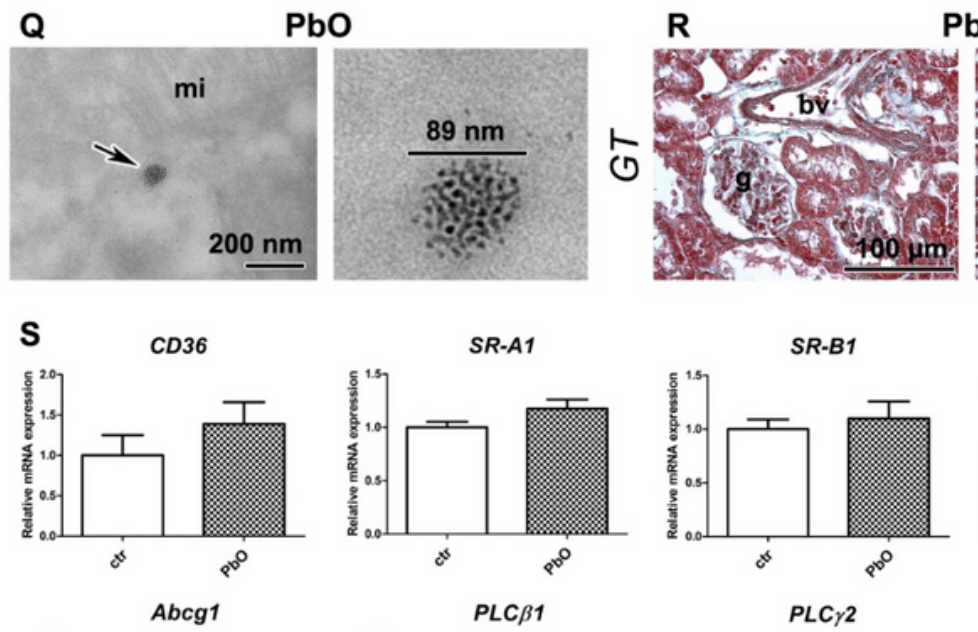

$\mathrm{PbO}$
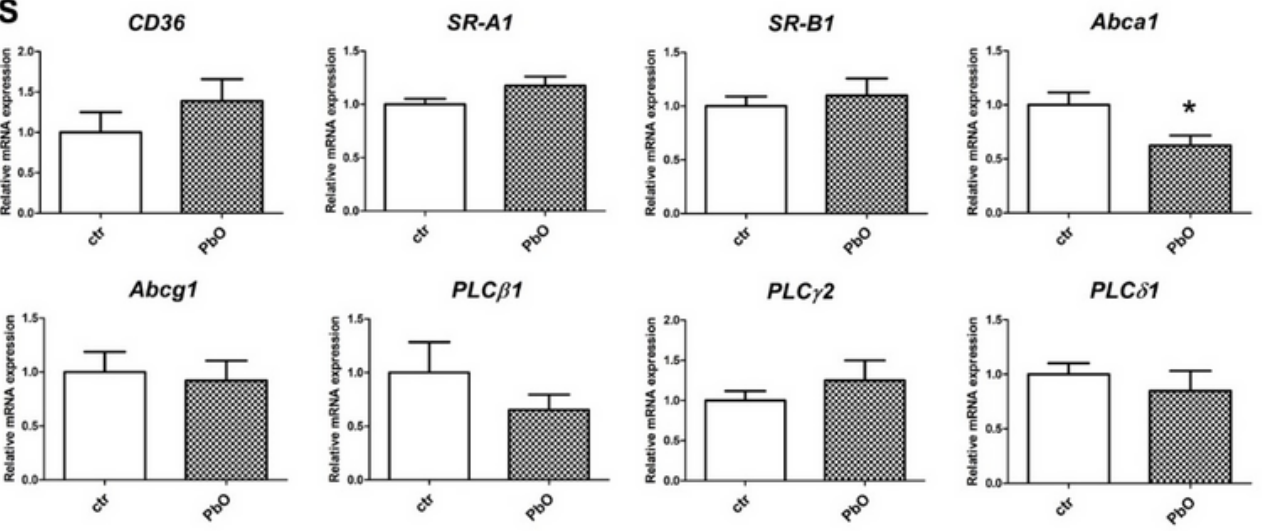

\section{Figure 6}

Kidney after 11-week PbO NP inhalation. A-C) Kidney in overview image in HE staining (cortex, outer medulla divided into outer and inner stripe - OSOM, ISOM, inner medulla - IM) in control (A) and PbO NP exposed animals $(B, C)$, arrow shows ureter. Scale bar in panels $A-C=1 \mathrm{~mm}$. D) Ureter in detail. E) Kidney cortex of control animals with glomerulus (g) and proximal (pt) and distal tubules. F, G) Kidney of PbO NPs treated samples exhibits metaplasia (arrow) of glomerular (g) parietal epithelium of Bowman's 
capsule (F) or dilatation of proximal tubules (pt, G). H) Kidney medulla without pathological alternations after exposure to PbO NPs. I-L) Detection of CD68-positive cells (marker of macrophages) in kidney (arrows). Scale bar in panels $=100 \mu \mathrm{m} . \mathrm{M}-\mathrm{Q}$ ) TEM images of kidney after inhalation of PbO NPs. M) Renal glomerulus (glo) of characteristic apperance. $\mathrm{N}$ ) typical podocyte (po) with pedicles, capillary with erythrocytes (er) and filtration barrier ( $\mathrm{fb}$ ) of kidney without pathological alteration. 0 ) Proximal tubule (pt) without damage. P) Large lipid vacuole (li) present in blood vessel. Q) Agglomerate of PbO nanoparticles in the epithelial cell of PT (arrow) next to mitochondria (mi). Scale bars are displayed individually for each picture. R) Collagen fibers stained with Green Trichrome (GT) were found predominantly around blood vessels (bv). Scale bar in panels $=100 \mu \mathrm{m}$. R) Gene expression of receptors CD36, SR-A1, Abca1, Abcg1, SR-B1, and phospholipases C after PbO NP inhalation. The graphs values indicate average $\pm S D$; * $p<0.05$ by unpaired t-test.

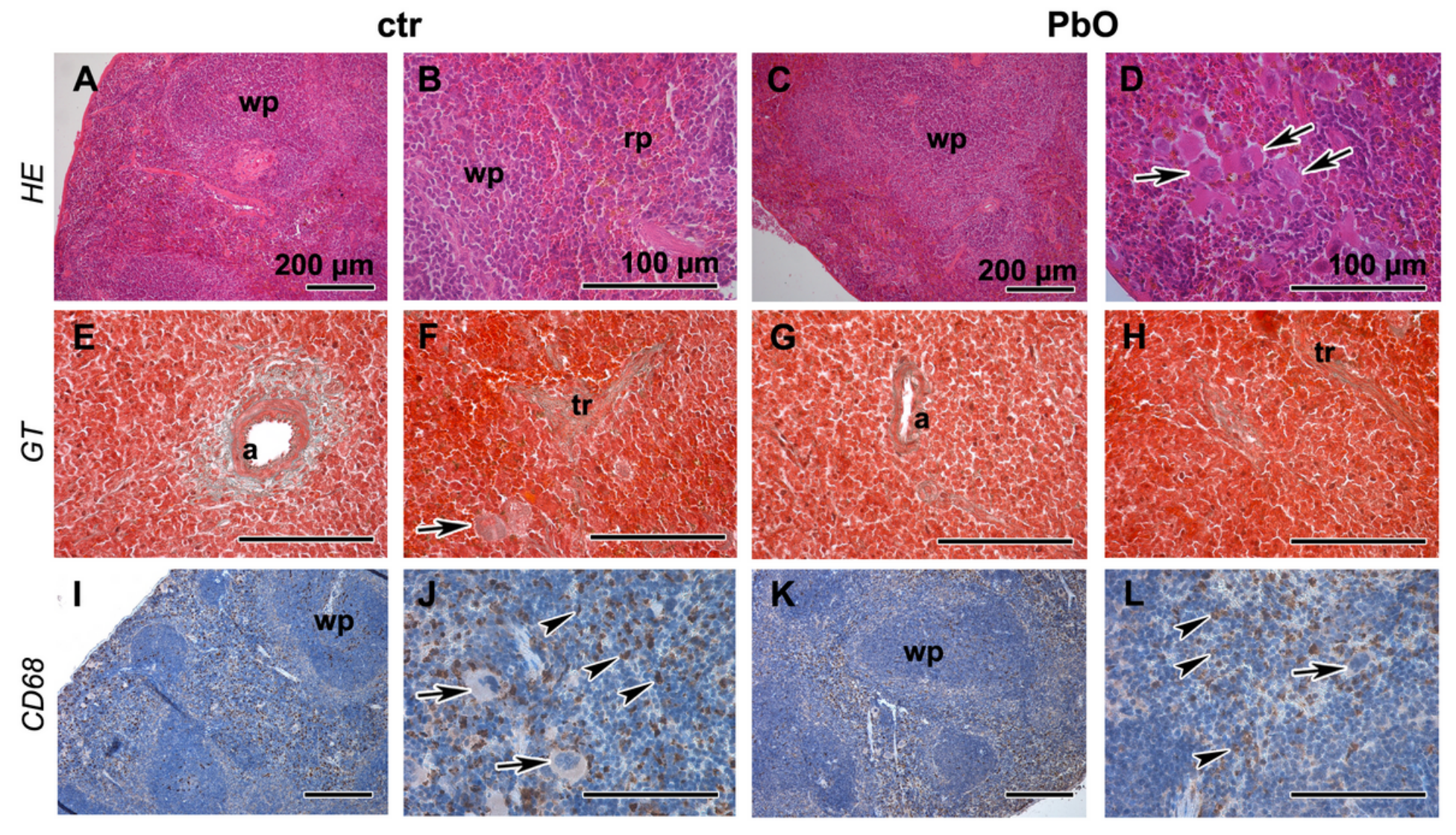

\section{Figure 7}

Spleen after 11-week PbO NP inhalation. A) Spleen of control animals. B, C) Spleen after exposure to PbO NPs. No significant changes were observed. D) Detail of red pulp with megakaryoblasts and megakaryocytes (arrows) in control animals. E, F) After PbO NP inhalation, there was increased number of megakaryoblasts or megakaryocytes (arrows). $r p-$ red pulp, wp - white pulp. Scale bar in all panels $=$ $100 \mu \mathrm{m}$.

\section{Supplementary Files}


This is a list of supplementary files associated with this preprint. Click to download.

- SmutnaetalPbOhighSupplementaryAug10.2021.docx 